\title{
COMPARATIVE THERMAL ECOLOGY OF COASTAL AND INLAND PACIFIC \\ RATTLESNAKES (CROTALUS OREGANUS)
}

\author{
A Thesis \\ presented to \\ the Faculty of California Polytechnic State University, \\ San Luis Obispo
}

In Partial Fulfillment

of the Requirements for the Degree

Master of Science in Biological Sciences

By

Hayley Layne Crowell

April 2019 
(C) 2019

Hayley Layne Crowell

ALL RIGHTS RESERVED 


\section{COMMITTEE MEMBERSHIP}

TITLE: $\quad$ Comparative thermal ecology of coastal and inland

Pacific rattlesnakes (Crotalus oreganus)

AUTHOR: $\quad$ Hayley Layne Crowell

DATE SUBMITTED: April 2019

COMMITTEE CHAIR: $\quad$ Emily Taylor, Ph.D.

Professor of Biological Sciences

COMMITEE MEMBER: Heather Liwanag, Ph.D.

Assistant Professor of Biological Sciences

COMMITTEE MEMBER: Benjamin Ruttenberg, Ph.D.

Associate Professor of Biological Sciences 


\author{
ABSTRACT \\ Comparative thermal ecology of coastal and inland \\ Pacific rattlesnakes (Crotalus oreganus) \\ Hayley Layne Crowell
}

Global biodiversity is declining as a direct result of anthropogenic climate change. Ectothermic species have become focal organisms for studying the ecological effects of altered climates due to the clear relationship between environmental temperatures and ectotherms' basic physiological functions. Historically, examinations of these effects have focused heavily on heliothermic lizards, and most others have tended to focus on single populations or sympatric species within a single community. Addressing the longterm energetic implications of environmental temperature variation will provide valuable insight into the cascading physiological effects that certain populations or species may experience as a result of altered climates.

In this study, we used thermal and behavioral data collected between 2010 and 2017 from four distinct populations of Pacific rattlesnakes (Crotalus oreganus) on the Central Coast of California. Two of these populations occupy thermally mild, coastal habitats while the other two occupy more thermally dynamic, inland habitats. Using operative temperature models, surgically implanted temperature loggers, and radiotelemetry, we collected data on the thermal microhabitats available within each of these study sites as well as field active body temperatures for 85 individual snakes. With the addition of a lab-derived preferred body temperature range, we determined the thermal quality of each site and the thermoregulatory accuracy of snakes from each population. Field behavioral observations, gathered from snakes at all four sites 
simultaneously during the year 2017, revealed how snakes utilize the thermal landscape and adjust thermoregulatory behavior to mitigate the effects of different climates. Although overall thermal quality was best at coastal sites, thermal quality of the microhabitats within each site varied greatly. Consistent with findings in other squamate reptiles, inland snakes thermoregulated more accurately, despite being in more thermally constrained environments. Despite the fact that coastal snakes had lower mean field active body temperatures, the preferred body temperatures of snakes were the same across all four sites. However, field active body temperatures were consistently lower than the preferred range, suggesting there are additional variables that influence thermoregulatory behavior.

Using established equations estimating the resting metabolic rates of snakes based on body mass and temperature, we calculated resting metabolic rate and annual baseline maintenance energy expenditure for each population. Coastal snakes, which had lower field active body temperatures, had overall lower metabolic rates than inland snakes, but upon correcting for mass, snakes at neither coastal nor inland sites differed in metabolic rates. Therefore, the majority of the differences observed in metabolic rates are driven by body size and not field-active body temperature. Inland snakes need, on average, approximately 1.6x more food annually than coastal snakes. Due to overall low resting metabolic rates, this translates to snakes at all sites needing less than one ground squirrel (their most common food item on the Central Coast) per year to fuel basic physiological functions.

Finally, we used conservative predictive climate change models allowing either $1^{\circ} \mathrm{C}$ or $2{ }^{\circ} \mathrm{C}$ increases to predict changes in the thermal quality of each site and ensuing 
changes in snake metabolic rates and maintenance energy expenditure. Due to the relatively high preferred body temperature of C. oreganus, thermal quality of the environment will actually increase under these climate models; due to an increase in ambient temperature, the proportion of hourly temperatures that fall within the preferred body temperature range will increase. If snake body temperature were to increase as the climate warms, a theoretical increase in body temperature of 1 and $2^{\circ} \mathrm{C}$ would have a low impact on the overall energetic needs of snakes, still allowing them to meet baseline maintenance energetic needs with only one large meal a year. Furthermore, we expect small increases in ambient temperature to have little impact on rattlesnakes because they are fairly precise thermoregulators, maintaining fairly constant body temperatures regardless of their thermal surroundings. Overall, our results show that studying the thermal ecology of multiple populations of a single species can reveal fine-scale information about the relationship between the thermal landscape and both ectotherm behavior and physiological processes. Additionally, our findings show that some species of large-bodied reptiles may be robust to modest thermal perturbations under conservative climate change predictions.

Keywords: thermal ecology, metabolism, climate change, energetic requirements thermoregulatory effectiveness, operative temperature model, Crotalus 


\section{ACKNOWLEDGEMENTS}

First and foremost, I want to thank my amazing team of undergraduate researchers ("Crotalus Prime") not only for pouring their hearts into such an enormous undertaking-of-a-project, but also for irreversibly altering my views on teaching and mentorship. Watching all of them progress from new lab volunteers to fully-fledged researchers absolutely confirms that mentoring in science is what I want to do for the rest of my life. I couldn't have done this without them.

I also want to thank my fellow PERL grad students (a.k.a. "Squa-mates") Luis Burgos, Kat Ivey and Heather Neldner for their help and unwavering support throughout the entirety of this project as well as the past graduate students of PERL who let me use their snake body temperature data for these analyses. Additionally, I owe an enormous debt of gratitude to my committee members Dr. Heather Liwanag and Dr. Ben Ruttenberg as well as Dr. Andrew Schaffner for their endless advice and patience as I navigated the grad school and thesis waters. In fact, I owe the entire Biology Department a huge thanks for always making me feel like family in a place so far from home.

There is a whole army of friends and family who have supported me from the beginning, but I'd especially like to thank Justin, Carissa, Christina and Matt for always being there and cheering me on, even in my hardest times. And of course, Mom and Dad, for letting me stay up late to watch Crocodile Hunter, keeping me grounded, and always encouraging me to pursue this dream.

And lastly, I'd like to thank Dr. Emily Taylor, not only for being an incredible mentor and advisor, but also a wonderful friend, and for teaching me that I am stronger than I gave myself credit for. 


\section{TABLE OF CONTENTS}

Page

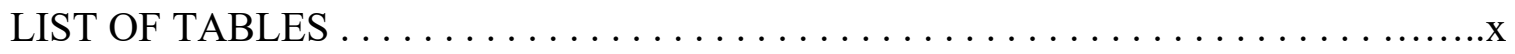

LIST OF FIGURES $\ldots \ldots \ldots \ldots \ldots \ldots \ldots \ldots \ldots \ldots \ldots \ldots \ldots \ldots \ldots \ldots \ldots \ldots \ldots$ CHAPTER

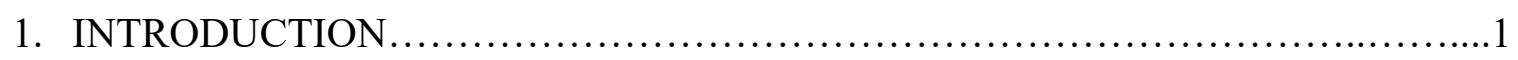

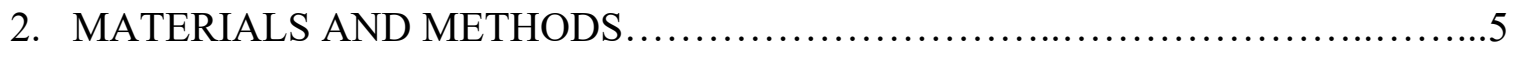

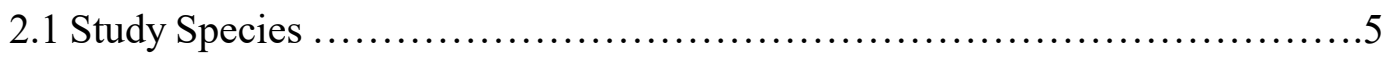

2.2 Study Sites...................................................... 5

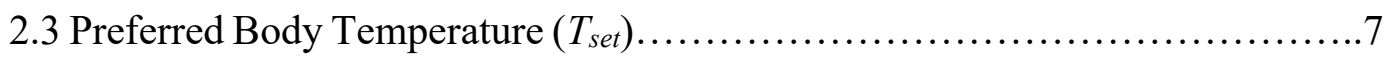

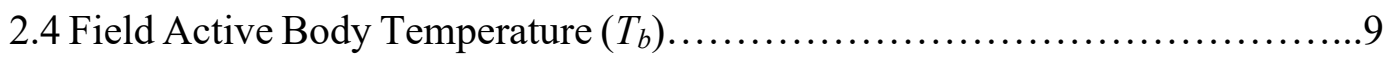

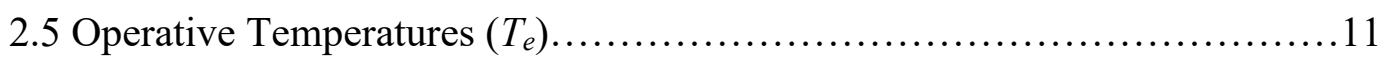

2.6 Thermal Ecology Variables Measured..................................13

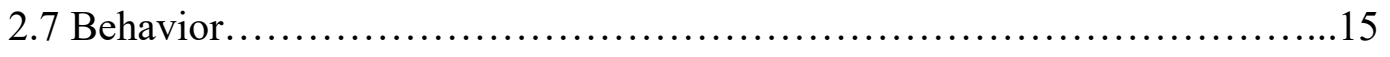

2.8 Energetics...................................................... 17

2.9 Climate Change Projections....................................... 18

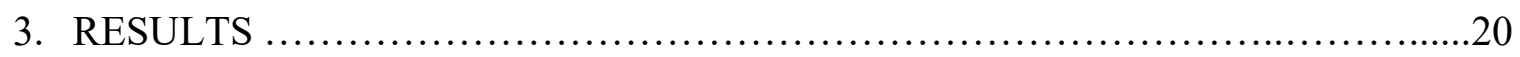

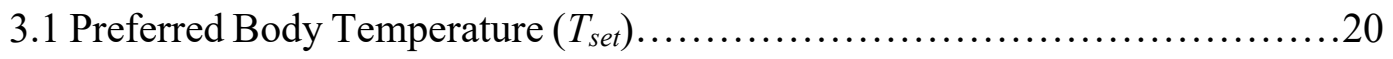

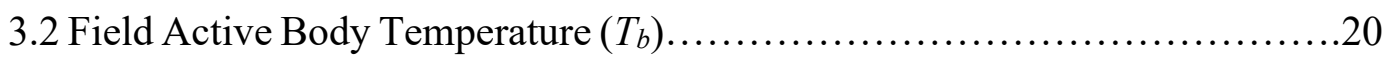

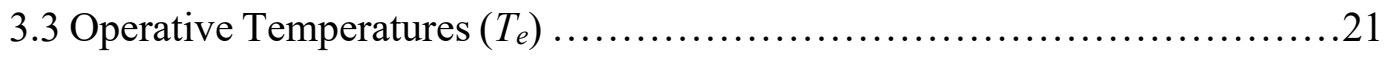

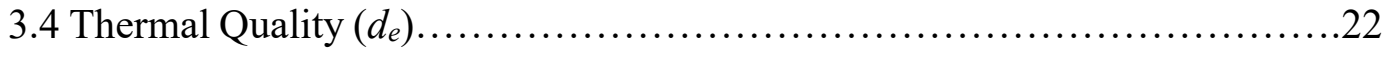

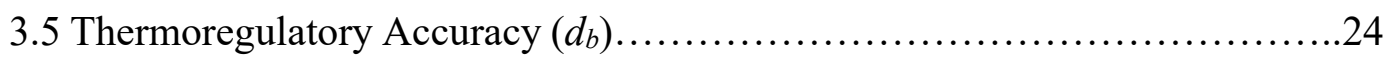

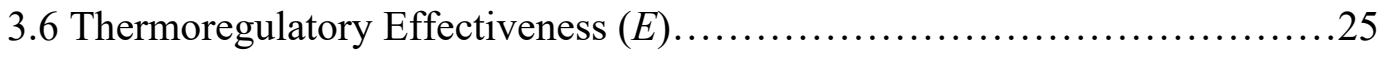


3.7 Behavior .26

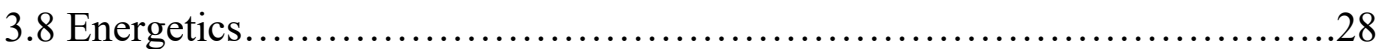

3.9 Climate Change Projections......................................... 31

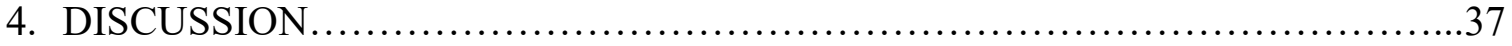

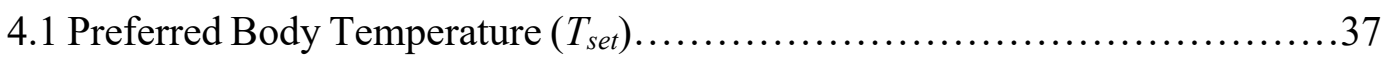

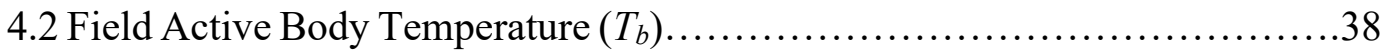

4.3 Operative Temperatures $\left(T_{e}\right)$ /Thermal Quality $\left(d_{e}\right) \ldots \ldots \ldots \ldots \ldots \ldots \ldots \ldots . \ldots . \ldots \ldots$

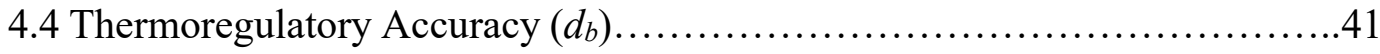

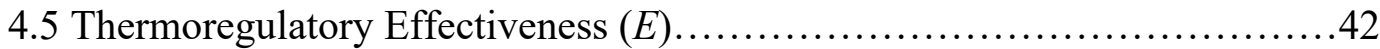

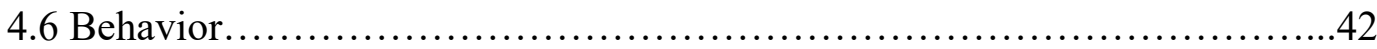

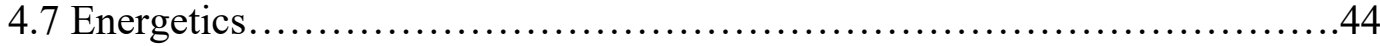

4.8 Climate change projections .......................................46

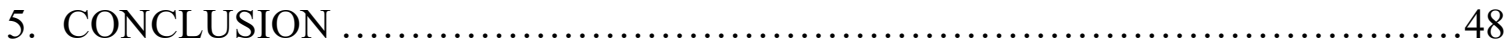

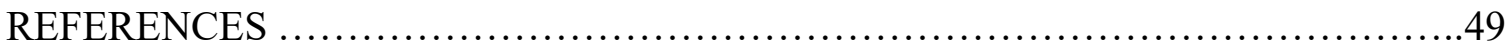

\section{APPENDICES}

A. Supplementary Tables...............................................62

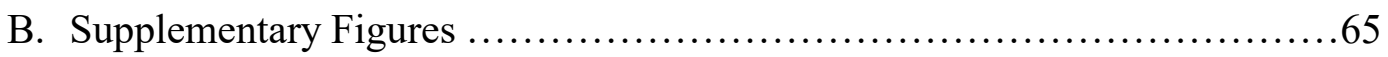




\section{LIST OF TABLES}

Table

Page

1. Nomenclature and definitions of frequently used thermal ecology and metabolism-related variables.

.7

2. Operative temperatures $\left(T_{e}\right)$ and thermal quality $\left(d_{e}\right)$ values for each OTM type at each of the four study sites from June 2017 to June 2018. Thermal quality values closer to zero are indicative of better thermal quality. Different letters indicate significant differences among OTM's of the same type.

*Mean $\mathrm{d}_{\mathrm{e}}$ for SG does not include exposed OTM values, as all exposed SG OTMs failed; therefore, mean $d_{e}$ is lower than would be expected if exposed values were included. Values followed by \pm 1 SEM.

3. Summary results of the repeated-measures ANOVA for the effects of site, month and time of day on overall mean $\mathrm{d}_{\mathrm{e}}$ of four field sites occupied by four distinct populations of Crotalus oreganus on the Central Coast of California.......

4. Mean indices of thermoregulatory effectiveness $(E)$ for the 2017 Crotalus oreganus active season (Apr-Oct). *Actual SG overall site mean $E$ is likely higher than reported and similar to that of the other inland site, CR. Exposed SG OTM continuously failed in the extreme daytime temperatures. 
5. Proportion of hourly operative temperatures from June 2017 to June 2018 , across four sites on the Central California Coast, that fall within the interquartile $\mathrm{T}_{\text {set }}$ range of $C$. oreganus with a $1^{\circ} \mathrm{C}$ and $2{ }^{\circ} \mathrm{C}$ increase in ambient temperature. Also note the year in which these temperature increases are expected to occur varies from site to site. Years were extrapolated using the most conservative RCP model (4.5).... .33

6. Mean number of ground squirrels required by an average-sized, adult male Crotalus oreganus from four distinct populations on the Central Coast of California in order to meet baseline annual maintenance energy requirements at current body temperature $\left(\mathrm{T}_{\mathrm{b}}\right)$ conditions and with a $1^{\circ} \mathrm{C}$ and $2^{\circ} \mathrm{C}$ increased in $T_{b}$ .36

7. Preferred body temperatures $\left(\mathrm{T}_{\mathrm{set}}\right)$ from Crotalus as well as other viper species. Notes indicate any discrepancies or points the authors thought were relevant to their study .38

S1. Environmental descriptions of four study sites on the Central Coast of California. Most notably for this study are the similarities in ambient temperatures and dominant vegetation within Inland and Coastal sites....

S2. Summary of $C$. oreganus morphometric data of snakes $(\mathrm{N}=45)$ used for preferred body temperature $\left(\mathrm{T}_{\text {set }}\right)$ trials, range of temperatures reached during trials and median site $\mathrm{T}_{\mathrm{se}}$

S3. Behavior states for C. oreganus with their corresponding designations. A behavior was recorded for individual snakes $(\mathrm{N}=28)$ for each observation performed via radio telemetry $(\mathrm{N}=1141)$. .63 
S4. Summary of mean masses and field active body temperatures $\left(T_{b}\right)$ of snakes used for theoretical resting metabolic calculations for each field site. Value

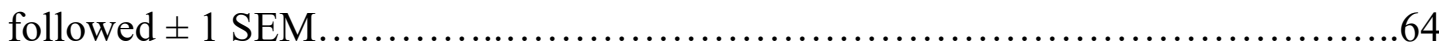




\section{LIST OF FIGURES}

Figure

Page

1a. Map of the locations on the Central Coast of California of the 4 distinct C. oreganus populations ( 2 coastal, 2 inland) used in this study $\ldots \ldots \ldots \ldots \ldots \ldots \ldots \ldots$

1b. Average monthly temperatures $\left({ }^{\circ} \mathrm{C}\right.$ ) for 4 study sites ( 2 inland, 2 coastal) on the Central Coast of California from 2010-2017 (National Ocean and Atmospheric Administration \& Western Regional Climate Center, 2017).............6

2. Least squares (LS) mean hourly field active body temperatures $\left(T_{b}\right)$ for four populations of $C$. oreganus $(\mathrm{N}=85 ; \mathrm{CR}=23, \mathrm{SG}=28, \mathrm{MDO}=15$, VAFB $=19$ ) on the Central Coast of California during the active season (April-Oct). Mean body temperatures differed significantly among sites, with Sedgwick having the highest mean body temperatures and Montaña de Oro with the lowest. A Tukey-Kramer post-hoc test showed no significant differences between $\mathrm{T}_{\mathrm{b}}$ within coastal or inland populations. Different letters represent a significant difference between means and bars represent $95 \%$ confidence intervals .21

3. Mean monthly operative temperatures $\left(T_{e}\right)$ for each of the four study sites on the Central Coast of California. Mean monthly $\mathrm{T}_{\mathrm{e}}$ differed significantly among sites but mean overall annual $\mathrm{T}_{\mathrm{e}}$ did not. $\mathrm{SG}$ mean temperatures are lower than actual expected site values due to the continuous failure of exposed OTMs in extreme summer temperatures. Grey bar represents the preferred body temperature range $\left(\mathrm{T}_{\mathrm{set}}\right)$ of Crotalus oreganus.....................22 
4. Mean thermoregulatory accuracy $\left(d_{b}\right)$ for each of the four populations of C. oreganus $(\mathrm{N}=85, \mathrm{CR}=23, \mathrm{SG}=28, \mathrm{MDO}=15, \mathrm{VAFB}=19)$ on the Central Coast of California. Values closer to zero mean higher thermal accuracy. Mean daily $d_{b}$ differed significantly among sites, with inland snakes (CR, SG) thermoregulating more accurately than coastal snakes (MDO, VAFB). A Tukey-Kramer post-hoc test revealed that inland sites did not significantly differ from one another, nor did coastal sites. Different letters represent a significant difference between means and bars represent $95 \%$ confidence intervals .25

5. Mean hourly operative and Crotalus oreganus body temperatures over the duration of the active season (Apr-Oct) for each of the four study sites (CR, SG, MDO, VAFB) on the Central Coast of California. CR and SG are inland sites and MDO and VAFB are coastal sites. Grey bars represent the preferred body temperature range $\left(\mathrm{T}_{\mathrm{set}}\right)$ of $C$. oreganus.........................26

6. Proportion of observed behaviors $(\mathrm{N}=1141)$ for four populations of Crotalus oreganus $(\mathrm{N}=85, \mathrm{CR}=23, \mathrm{SG}=28, \mathrm{MDO}=15, \mathrm{VAFB}=19)$ on the Central Coast of California during the active season (April-October 2017). Snakes at CR (hotter conditions) were hiding more frequently when compared to all other sites and snakes at MDO (mild conditions) were hiding less frequently when compared to all other sites. Column widths reflect the number of behavioral observations per site .28 
7. Probability predictions for observing Crotalus oreganus $(\mathrm{N}=85 ; \mathrm{CR}=23$, $\mathrm{SG}=28, \mathrm{MDO}=15, \mathrm{VAFB}=19)$ behaviors across a range of ecologically relevant air temperatures $\left(9-31^{\circ} \mathrm{C}\right)$ for four distinct populations on the Central Coast of California. CR and SG represent inland populations and MDO and VAFB represent coastal populations. Air temperature was a significant predictor for ambush and transit behaviors but not for basking, hiding or resting. Field site was a significant predictor for basking and hiding but not for ambush, resting, or transit behaviors.

8a. Mean daily resting metabolic rates $\left(\mathrm{ml} \mathrm{O}_{2} /\right.$ day) of adult, male C. oreganus $(\mathrm{N}=85 ; \mathrm{CR}=23, \mathrm{SG}=28, \mathrm{MDO}=15, \mathrm{VAFB}=19)$ from four different populations (two inland, two coastal) in Central California (based on established metabolic equations from Beaupre \& Duvall, 1998). Snakes from inland sites have significantly higher metabolic rates than snakes from coastal sites. Different letters represent a significant difference between means and standard error bars represent \pm 1 SEM

8b. Mass-specific daily standard metabolic rates $\left(\mathrm{ml} / \mathrm{O}_{2} /\right.$ day $\left./ \mathrm{g}\right)$ of adult, male C. oreganus $(\mathrm{N}=85 ; \mathrm{CR}=23, \mathrm{SG}=28, \mathrm{MDO}=15, \mathrm{VAFB}=19)$ from four different populations ( 2 inland, 2 coastal) in Central California. There was no significant difference among the mass corrected metabolic rates at any of the sites. Standard error bars represent \pm 1 SEM. 
9. Number of ground squirrels (Otospermophilus beecheyi) an average, adult male Crotalus oreganus from four distinct populations on the Central Coast of California (CR, SG, MDO, VAFB) would need to consume in order to meet annual baseline energetic requirements. .32

10. Mean monthly operative temperatures $\left(T_{e}\right)$ for each of the three operative temperature model types (Burrow, Intermediate, Exposed) at current conditions (black line) and with a $1^{\circ} \mathrm{C}$ (dark grey line) and $2^{\circ} \mathrm{C}$ (light grey line) increase in ambient temperature for four sites (CR, SG, MDO, VAFB) on the Central Coast of California. CR and SG represents inland locations and MDO and VAFB represent coastal locations. Grey bars represent the preferred body temperature $\left(\mathrm{T}_{\mathrm{set}}\right)$ of Crotalus oreganus .34

11. Overall thermal quality $\left(d_{e}\right)$ for four study sites $(C R, S G, M D O, V A F B)$ on the Central Coast of California at current conditions and with a $1{ }^{\circ} \mathrm{C}$ and $2{ }^{\circ} \mathrm{C}$ increase in ambient temperatures. All sites experience an overall increase in $\mathrm{d}_{\mathrm{e}}$ as ambient temperatures increase, creating potentially more favorable thermal environments for $C$. oreganus in both coastal and inland locations. Error bars represent \pm 1 SEM.

$\mathrm{S} 1$. Median preferred body temperatures $\left(\mathrm{T}_{\mathrm{set}}\right)$ of snakes from each site with $25^{\text {th }} \%$ and $75^{\text {th }} \%$ quartiles. There are no significant differences in $\mathrm{T}_{\text {set }}$ at the four sites after taking into account size, sex, presence of internal radio transmitter and season. The mean $\mathrm{T}_{\text {set }}$ of all populations was $29.22 \pm 0.92{ }^{\circ} \mathrm{C}$ with an interquartile range of $26.3 \pm 1.01-32.3 \pm 0.84^{\circ} \mathrm{C}$ 


\section{Introduction:}

Reptile diversity across the globe is declining as a direct result of anthropogenic climate change (Gibbons et al., 2000; Araújo et al., 2006; Whitfield et al., 2007; Bickford et al., 2010 Ihlow et al., 2011; Böhm et al., 2013; Urban, 2015). As ectotherms, reptiles depend heavily on their immediate surroundings to regulate body temperature, where even slight changes in environmental conditions can have serious implications for basic physiological functions, including metabolism, growth, reproduction, movement, and more (Huey, 1982; Walther et al., 2002; Besson \& Cree, 2010). In turn, changes in the thermal environment can have profound effects from the level of the organism up to the ecosystem (Grigaltchik et al., 2012). However, behavioral thermoregulation may mitigate the impacts of climate change within a broad temperature window (Bogert, 1949; Brown et al. 2000; Kearney et al., 2009; Sinclair et al., 2016). Recently, the availability of highresolution climate change forecasts and technology for modeling thermal landscapes has allowed researchers to begin quantifying the current and predicted effects of climate change on diverse species (Sinervo et al., 2010; Brusch et al., 2016).

In light of these new climate-monitoring technologies and prediction tools, reptiles, especially heliothermic lizards, have been the focus of many climate-based studies, partly due to their well-defined thermal behaviors and the ability to obtain large sample sizes with limited effort (Gibbons et al., 2000; Araújo et al., 2006; Aubret \& Shine, 2010; Sinervo et al., 2010; Clusella-Trullas et al., 2011; Ihlow et al., 2011; Pelegrin \& Bucher, 2012). However, most of these studies only use single populations of a given species and/or focus on sympatric species in a single community (Moore, 1978; Beck, 1995; Sinervo et al., 2010; Gunderson \& Leal, 2012), limiting their scope to certain 
localities and preventing inferences about the possibility that climate change and environmental variation will interact in their future impacts on species. Furthermore, many of these studies have focused on the direct impacts of altered temperatures on the body temperature $\left(T_{b}\right)$ of the organism itself while failing to address the implications of changing $\mathrm{T}_{\mathrm{b}}$ on annual energetic costs, metabolic rates over time, and activity patterns (Waldshmidt et al. 1986; Alford \& Lutterschmidt, 2012). To the best of our knowledge, no study to date has compared the thermoregulatory effectiveness and energetic requirements of a given species (particularly a large-bodied reptile) across multiple populations that inhabit distinct thermal environments.

A powerful tool for evaluating the thermal ecology of ectotherms is the use of operative temperature models (OTMs). These biophysical models can be used to quantify the thermal landscape potentially available to animals and in turn, calculate the thermal quality of microhabitats (Lutterschmidt \& Reinert, 2012). Thermal quality of the environment directly affects the amount of time and energy that must be expended to maintain $\mathrm{T}_{\mathrm{b}}$ within the preferred range (Hertz et al., 1993; Row et al. 2006). OTMs serve as null models for the distribution of body temperatures experienced by a nonthermoregulating ectotherm. The physical properties of an OTM are designed to match the thermal properties (e.g. inertia, reflectance, etc.) of the study organism of interest (Hertz et al., 1993), meaning that the data downloaded from the OTM temperature logger will represent the temperatures that a given individual could attain if it were to be in that specific microhabitat (Dzialowski, 2005). Over the past 35 years, OTMs have greatly enhanced our understanding of how ectotherms thermoregulate in various habitats (Bakken \& Gates, 1975; Bakken, 1992; Dzialowski, 2005), and they can provide insights 
into the looming effects of climate change on reptiles. OTMs help scientists measure the effects of thermal environments on an organism's physiology and ecology by combining multiple environmental factors into "a single thermal metric on a spatial scale appropriate for the organism of interest” (Dzialowski, 2005). By deploying multiple OTMs at each study site during the same time period, we can accurately capture and compare the range of potential temperatures (thermal landscape) available to a reptile in a variety of microhabitats across ecosystem type and latitude. OTMs have been used in a variety of ecological studies investigating thermal variation among snake species contained within a single, homogenous ecosystems (Blouin-Demers \& Weatherhead, 2001; Blouin-Demers et al., 2002; Lelièvre et al. 2011; Bovo et al., 2012).

Here, we examine the thermal ecology of a large-bodied reptile, the Pacific rattlesnake (Crotalus oreganus), across multiple populations while also extending our inference to quantify the energetic implications of environmental variation. Unlike small lizards, rattlesnakes have extraordinarily low metabolic rates (on a mass-specific basis), from one-fifth to one-half of the average metabolic rates of other snakes (Beaupre \& Duvall, 1998a). Metabolic rates and energetic allocation to various physiological functions in rattlesnakes are well-established (Beaupre \& Duvall 1998a; Beaupre \& Duvall 1998b) and other rattlesnake life history traits (such as large body size, dense populations, high biomass conversion efficiencies, and simple behaviors) have made them excellent models for field bioenergetic studies (Klauber, 1972; Beaupre, 2002). We combine an intensive field study with eight years of physiological and behavioral data from four field sites on the Central Coast of California to quantify the thermal ecology and energy requirements of snakes on a macroecological scale. We then paired these data 
with field-active temperature and behavioral observations to predict how thermal constraints on snake annual maintenance energy expenditures will affect these organisms in a warming world. This project represents one of the most comprehensive studies to date on the effects of climate change on the physiological ecology of a reptile.

The objectives of this study were to (1) quantify the thermal ecology and the annual maintenance energy expenditures for Pacific rattlesnakes from four populations on the Central California coast and (2) incorporate climate change models with rattlesnake thermoregulatory data to predict changes in habitat thermal quality and potential ensuing physiological and behavioral constraints due to anthropogenic climate change.

We hypothesized that precise thermoregulation and low metabolic rates would allow rattlesnakes to respond to variable thermal environments effectively, both now and in the future due to climate change. Specifically, we predicted that the thermal quality of habitats would differ, with the inland sites having a lower overall thermal quality than the stable coastal sites. Additionally, due to the climatic differences between these two study site types, we predicted that coastal snakes would have lower field active body temperatures than inland populations and exhibit more active thermoregulatory behavior as a means of reaching their preferred body temperature. For these reasons, we predicted that rattlesnakes in mild, coastal habitats would have lower annual maintenance energy expenditures than snakes at inland habitats and would be less thermally constrained both currently and in the future. 


\section{Materials and Methods:}

\subsection{Study species}

The Pacific Rattlesnake (Crotalus oreganus) is a medium-sized rattlesnake that is found in western North America from southern British Columbia south to Baja, Mexico (Pook et al., 2000; Sunagar et al., 2014). The exact classification of this species is still under debate and our four study sites fall in the integration zone of the northern $(C . o$. oreganus) and southern (C. o. helleri) subspecies (Ashton \& Queiroz, 2001). However, recent evidence suggests that our study populations genetically cluster (Holding et al., 2018) so for the purpose of this study, we are hereby referring to them as C. oreganus. They are habitat and dietary generalists found in coastal scrub, chaparral, oak woodland, montane forests, grasslands, and deserts, and they prey primarily on small mammals and lizards (Mackessy et al., 2003; Sunagar et al., 2014, Sparks et al., 2015). Body size varies widely among localities, but typical snout-vent lengths (SVLs) of adult male $C$. oreganus in California range from approximately $60 \mathrm{~cm}$ to $120 \mathrm{~cm}$, with males being typically larger than females (Ashton, 2001; Aldridge, 2002). The active season is usually from late March to October with peaks in April and August and a lull in activity in June and July (Fitch, 1949).

\subsection{Study sites}

The four study sites used for this investigation were the Chimineas Ranch in the Carrizo Plain Ecological Reserve (CR), Montaña de Oro State Park (MDO), the University of California's Sedgwick Reserve (SG), and Vandenberg Air Force Base (VAFB; Figure 1). MDO and VAFB are coastal sites characterized by rugged cliffs, canyons, and coastal 
scrub plant communities that experience relatively stable and mild seasonal temperatures (Underwood et al., 2003; Capehart et al., 2016). CR and SG are inland sites that experience a wider range of daily and seasonal temperatures and are dominated primarily by chaparral, oak savanna, and grassland plain habitats (Chimineas Ranch Foundation, 2019; University of California Reserve System: Natural Resources, 2019). CR and MDO are situated north of the other two and are in San Luis Obispo County, CA, USA, whereas SG and VAFB are in Santa Barbara County, CA, USA, Table S1).
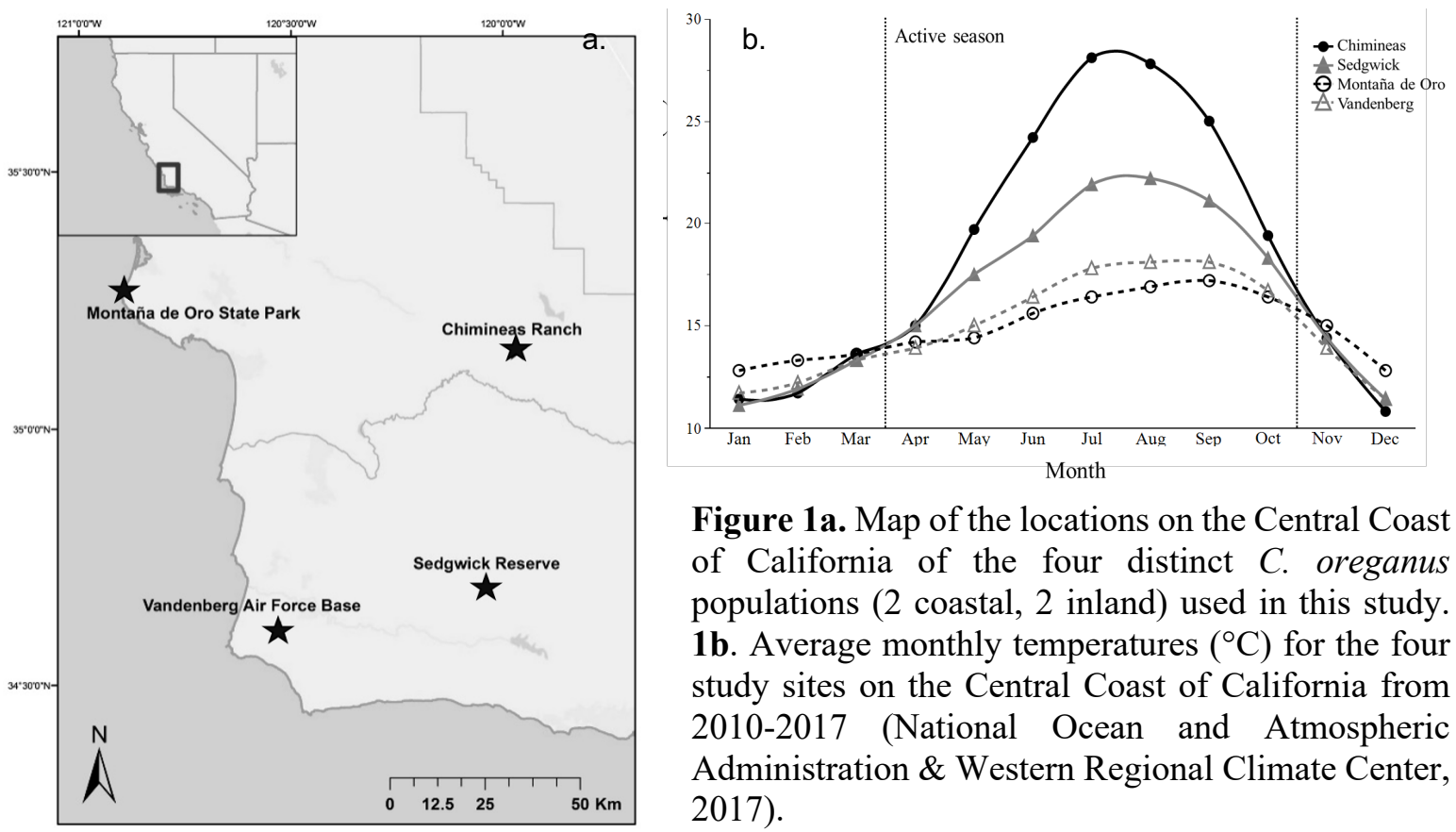

Figure 1a. Map of the locations on the Central Coast of California of the four distinct $C$. oreganus populations ( 2 coastal, 2 inland) used in this study. 1b. Average monthly temperatures $\left({ }^{\circ} \mathrm{C}\right)$ for the four study sites on the Central Coast of California from 2010-2017 (National Ocean and Atmospheric Administration \& Western Regional Climate Center, 2017). 
Table 1. Nomenclature and definitions of frequently used thermal ecology and metabolism-related variables.

\begin{tabular}{|c|c|}
\hline Nomenclature & Definition \\
\hline OTM & $\begin{array}{l}\text { operative temperature model, physical model with the same radiative and } \\
\text { thermal properties of a non-thermoregulating organism, used to evaluate the } \\
\text { range of environmental temperatures potentially available to said organism }\end{array}$ \\
\hline $\mathrm{T}_{\mathrm{b}}$ & body temperature $\left({ }^{\circ} \mathrm{C}\right)$ \\
\hline $\mathrm{T}_{\mathrm{e}}$ & operative temperature $\left({ }^{\circ} \mathrm{C}\right)$, the temperatures collected by OTMs \\
\hline $\mathrm{T}_{\text {set }}$ & $\begin{array}{l}\text { preferred body temperature, usually represented as a } 50 \% \text { interquartile range } \\
\text { from a group of body temperatures selected by an organism or set of } \\
\text { organisms in a laboratory thermal gradient }\left({ }^{\circ} \mathrm{C}\right)\end{array}$ \\
\hline$d_{b}$ & $\begin{array}{l}\text { thermoregulatory accuracy, the absolute value of the difference between field } \\
\text { measured } \mathrm{T}_{\mathrm{b}} \text { and the animal's } \mathrm{T}_{\mathrm{set}}\end{array}$ \\
\hline$d_{e}$ & $\begin{array}{l}\text { habitat thermal quality, the absolute value of the difference between field- } \\
\text { measured } T_{e} \text { and the animal's } T_{\text {set }}\end{array}$ \\
\hline $\mathrm{E}$ & $\begin{array}{l}\text { thermoregulatory effectiveness, the difference between } 1 \text { and the quotient of } \\
d_{b} \text { and } d_{e}\end{array}$ \\
\hline RMR & $\begin{array}{l}\text { resting metabolic rate, the metabolic rate of a resting, fasted animal at any } \\
\text { given time of day }\end{array}$ \\
\hline
\end{tabular}

\subsection{Preferred Body Temperature $\left(T_{\text {set }}\right)$}

In order to quantify how carefully an organism thermoregulates in a given environment, we must first know its preferred body temperature $\left(T_{\text {set; }}\right.$ Table 1$)$, which was unknown for $C$. oreganus prior to this investigation. $\mathrm{T}_{\text {set }}$ is typically reported as the interquartile range (IQR) of body temperatures selected by post-absorptive, thermoregulating animals that have access to a full range of biologically relevant thermal conditions, typically in the form of a laboratory thermal gradient, without environmental pressures such as basking influence, predation, competition, etc. (Dawson, 1975; Huey, 1982; Blouin-Demers \& Weatherhead, 2001). To determine $\mathrm{T}_{\text {set, }}$ a laboratory thermal 
gradient was used to present a range of ecologically relevant temperatures $\left(8-46^{\circ} \mathrm{C}\right)$ following the design protocol of Bovo et al. (2012). The gradient consisted of three lanes (250 x $20 \times 25 \mathrm{~cm}$ each), separated by solid, wooden dividers, and was lined with approximately $3 \mathrm{~cm}$ of sand to avoid the possibility of snakes getting burned on the metal floor of the trial arena. The gradient was designed with closed water circuits running at both ends, with a water heater (Stiebel Eltron model no. SHC4, Holzminden, Germany) on the hot side and a water cooler on the cold side (ActiveAQUA Refrigerateur model no. AACH10, Petaluma, CA, USA). The water passed through copper pipes attached to the underside of the metal floor of the gradient; the pipes were covered with thick fiberglass insulation and dense foam boards on the bottom to reduce heat loss to the room. The distance between pipes increased as they approached the center point of the gradient to ensure that the heat transfer became more dispersed in the center.

Snakes of varying size $(35 \mathrm{~cm}-108.4 \mathrm{~cm})$ and $\operatorname{sex}(\mathrm{N}=45, \mathrm{~m}=41, \mathrm{f}=4)$ were collected from all four field sites opportunistically from September 2017 - June 2018 (Table S2). Snakes were brought back to the California Polytechnic State University campus, where basic morphometrics (mass, SVL), sex, as well as reproductive status and presence of gut contents were recorded. If snakes were found to have visible meals in their gut or detectable follicles/offspring, these snakes were excluded from the analysis as these factors could dramatically alter preferred temperatures. Subsequently, thermocouples (model no. 5SRTC-TT-K-40-72, Omega Engineering, Egham, Surrey, United Kingdom) were inserted into the snakes' cloacae and held in place via surgical tape wrapped around the base of the tail. The thermocouples were connected to a data logger (model no. RDXL4SD, Omega Engineering, Egham, Surrey, United Kingdom) 
that automatically recorded the snakes' internal body temperatures every ten minutes. Snakes remained in the gradient for a 2-hour acclimation period (Bovo et al., 2012) followed by a 12 -hour recording period. The gradient was located in a room with consistent lighting and temperature (between $22-25^{\circ} \mathrm{C}$ ) to reduce the effects of diel activity patterns and circadian rhythm on behavior, as trials were constantly running in order to maximize the number of snakes tested. Once snakes finished their trial, they were removed, and sand was mixed and cleaned as needed to reduce the effects of scent on the behavior of new trial animals. The data were downloaded from the logger's SD card and analyzed in JMP v13.2.1 (JMP ${ }^{\circledR}$, SAS Institute Inc., Cary, NC, USA. 19892007). Median body temperature of each snake during the 12-hour trial period was used for statistical analysis of $\mathrm{T}_{\text {set }}$ variables (Blouin-Demers \& Weatherhead, 2001; Fitzgerald et al. 2003), and an ANCOVA was performed to examine how site, sex, mass, season (Charland, 1990) or presence of internal radio transmitter significantly affected median $\mathrm{T}_{\text {set. }}$ We used $\alpha=0.05$ for this and all following statistical analyses (unless otherwise noted). Following a significant p-value, the appropriate post-hoc test was conducted. Means reported are followed by \pm 1 SEM unless otherwise noted.

\subsection{Field Active Body Temperatures $\left(T_{b}\right)$}

A total of 106 adult, male rattlesnakes were collected between the years of 20102017 across each of the four study sites. Seventy-eight of these snakes $(\mathrm{CR}=22, \mathrm{SG}=$ $27, \mathrm{MDO}=11, \mathrm{VAFB}=18$ ) were subjects of previous studies that had also been implanted with internal temperature loggers similar to the procedure described below; temperature data from these snakes will be referred to as the "historical" data. In order to 
collect standardized observations across the same year, 28 additional snakes were collected in spring of 2017 from all four sites: five from CR, eight from SG, eight from MDO, and 7 from VAFB. Rattlesnakes were captured at their respective field sites and transferred to the laboratory where morphological data (i.e., SVL, mass) were recorded. They were housed individually in 71.12 x 60.96 x $30.48 \mathrm{~cm}$ enclosures (Model V221, LLL Reptile and Supply Company, Inc., Vista, California, USA). Surgical implantation of radio-transmitters (see below) was performed within 1-2 days of capture. Prior to surgery, the snake's head was secured in a plastic restraining tube (Midwest Tongs, Greenwood, MO, USA) to allow safe handling and the snake was anesthetized with isoflurane (Vet One, MWI, USA). Rattlesnakes were then surgically implanted with Holohil radio-transmitters (models SB-2, 5.2g and SI-2,11 g, $13.5 \mathrm{~g}$; assigned to snakes based on their mass; Holohil Systems Ltd., Carp, Ontario, CA) following the procedures of Claunch et al. (2017). Additionally, snakes were implanted with Thermochron iButtons (DS1922L-F5 and DS1921G-F5 models, Maxim Integrated Products Inc., Rio Robles, San Jose, CA), which were set to record field active body temperatures $\left(T_{b}\right)$ every hour. Plasti Dip (Model 11603-6, Plasti Dip International, Blaine, MN, USA) was used to waterproof iButtons two days prior to implantation. The transmitters and iButtons were sterilized in Benz-All (Xttrium Laboratories, Inc., Chicago, IL, USA) for at least 24 hours prior to implantation. Immediately following surgery, acrylic paint was injected into the three proximal rattle segments in unique color combinations to allow for accurate field identification of individual snakes (Taylor et al., 2004; Taylor \& DeNardo, 2005; Lind et al., 2010; Putman et al., 2013). Snakes were then returned to their enclosures and allowed to recover in the lab for at least 24 hours prior to release. Rattlesnakes were 
collected under California Department of Fish and Wildlife Scientific Collecting Permit \# SC-13618, and experimental procedures were approved by the California Polytechnic State University Institutional Animal Care and Use Committee (Protocol \#1704).

At the end of the study, snakes were recaptured and brought back to the laboratory to remove iButtons and radio-transmitters. The iButton data were downloaded using the program One Wire Viewer (OneWireViewer, Version 3.19.47., Maxim Integrated, San Jose, CA, USA. 2001-2015). Unfortunately, 21 of 28 snake $T_{b}$ loggers experienced early battery failure and our overall sample size for $T_{b}$ analysis was reduced to $\mathrm{N}=85$ ( $\mathrm{n}=7$ for 2017). To compare the mean field active $\mathrm{T}_{\mathrm{b}}$ of snakes across the four sites, we used a mixed-effects model with an $\mathrm{AR}(1)$ covariate structure to capture the serial correlation of the within-snake observations of temperature (Millar \& Anderson, 2004). Site, month, and time of day acted as fixed effects, snake ID was added as a random effect, and a unique time of day/date value for each data point was used as for the repeated structure. Additional sin and cos transformed time of day variables were also included as fixed effects in order to account for the cyclic, continuous nature of time. Significant findings were followed by a Tukey-Kramer post-hoc test.

\subsection{Operative Temperatures $\left(T_{e}\right)$ :}

Operative temperature models (OTMs) were deployed in various locations throughout the four field sites to determine the fine-scale thermal landscapes potentially available to each of the rattlesnake populations. Operative temperature $\left(T_{e}\right)$ is defined as the "temperature of an inanimate object of zero heat capacity with the same size, shape, and radiative properties as the animal exposed to the same environment" (Bakken \& 
Gates, 1975). OTMs were $40 \mathrm{~cm} \times 2.5 \mathrm{~cm}$ copper pipes filled with water and capped at one end with a screw-on PVC cap and at the other with a welded-on copper cap (Bakken, 1992; Lutterschmidt \& Reinert, 2012). Each pipe was painted with a base layer of mixed Rust-Oleum (C "Matte Burlap" and "Multicolor textured" tan spray paints. A dorsal diamond pattern similar to that of a live C. oreganus was painted in "Matte bittersweet" dark brown (Rust-Oleum Corporation, Vernon Hills, IL, USA). A Thermochron iButton temperature data logger (model no. DL1922, Maxim Integrated Products Inc., Rio Robles, San Jose, CA) was suspended in the center of each pipe by a 3D-printed, plastic mount that prevented the iButton from touching any of the surrounding pipe walls to avoid direct conduction from the metal pipe to the data logger (Bakken, 1992). $T_{e}$ was recorded every hour for one year from June 2017 to June 2018. Five OTMs were placed at each of the four study sites in various microhabitats (Blouin-Demers \& Weatherhead, 2002; Lutterschmidt et al. 2012): two inside typical snake refugia (e.g., ground squirrel burrows, rock burrows), two in exposed habitat (open field, gravel road), and one in an intermediate habitat (under a shrub or bush). OTMs were validated using two averagesized $(570 \mathrm{~g}, 740 \mathrm{~g})$ adult rattlesnake carcasses of similar width that had recently been found dead on the road. Snake carcasses and three OTMs (implanted with iButtons in the same fashion as their respective experimental field counterparts, programmed to take a temperature reading every 10 minutes) were cooled in a fridge for 1 hour and then placed outside on leaf litter, under direct sunlight for $2.5 \mathrm{~h}$. OTMs tended to heat slightly faster than snake carcasses but OTM temperature and snake carcass temperatures were highly correlated and validated using a Pearson linear regression (snake carcass $=0.63+(1.05 *$ OTM $\left.), \mathrm{r}^{2}=0.97, \mathrm{~F}_{1,14}=496.21, \mathrm{p}<0.0001\right)$. 


\subsection{Thermal Ecology Variables Measured:}

Thermal indices developed in recent years (Hertz et al, 1993) are now commonly used to compare the extent to which an animal actually experiences body temperatures $\left(T_{b}\right)$ within its preferred range ( $\left.T_{\text {set }}\right)$ and the extent to which the habitat in which it lives allows $\mathrm{T}_{\mathrm{b}}$ to be reached within $\mathrm{T}_{\text {set }}$ (Blouin-Demers \& Weatherhead, 2001). The three main variables used to make this comparison are thermal quality $\left(\mathrm{d}_{\mathrm{e}}\right)$, thermoregulatory accuracy $\left(\mathrm{d}_{\mathrm{b}}\right)$ and thermoregulatory effectiveness $(E$; Table 1$)$.

1. Thermal quality of the environment $\left(\mathrm{d}_{\mathrm{e}}\right)$ is calculated as the absolute value of the difference between the operative temperature $\left(\mathrm{T}_{\mathrm{e}}\right)$ and the preferred body temperature of the snakes $\left(T_{\text {set }}\right)$.

$$
\mathrm{d}_{\mathrm{e}}=\left|\mathrm{T}_{\text {set }}-\mathrm{T}_{\mathrm{e}}\right|
$$

High values of $d_{\mathrm{e}}$ mean that the thermal quality of the environment is low. Thermal quality values approaching "0" represent more favorable thermal habitat.

2. Thermoregulatory accuracy $\left(\mathrm{d}_{\mathrm{b}}\right)$ is calculated as the absolute difference between the field active body temperatures $\left(T_{b}\right)$ and the $T_{\text {set. }}$.

$$
\mathrm{d}_{\mathrm{b}}=\left|\mathrm{T}_{\mathrm{set}}-\mathrm{T}_{\mathrm{b}}\right|
$$

High values of $d_{b}$ mean low thermoregulatory accuracy (i.e., the snake's actual body temperature is much higher or lower than its $\left.\mathrm{T}_{\text {set }}\right)$.

3. Thermoregulatory effectiveness $(\mathrm{E})$ is calculated as the difference between 1 and the quotient of $\mathrm{d}_{\mathrm{b}}$ and $\mathrm{d}_{\mathrm{e}}$.

$$
E=1-\left(d_{b} / d_{e}\right)
$$

A positive value approaching 1 shows that a snake is thermoregulating carefully; a value approaching zero implies random selection of microhabitats irrespective of their thermal 
quality; and a negative value shows snakes are avoiding thermally favorable microhabitats (Hertz et al. 1993; Blouin-Demers et al., 2001).

Thermal calculations were done in R v. 3.4.4 (R Development Core Team, 2015) using the package "dplyr" (François et al., 2018), and statistical analyses were done in JMP Statistical Analysis software v. 14.0.0.

Due to OTMs exceeding the temperature limits of the iButton temperature loggers, all exposed OTMs at SG failed (along with their replacements) and no exposed $T_{e}$ values were included for the calculations for SG. To compare $T_{e}$ values across different sites, we used a mixed model with an AR(1) covariate structure similar to the model used for $\mathrm{T}_{\mathrm{b}}$ (see above section on body temperature) followed by a Tukey-Kramer post-hoc test. The same statistical analysis was also performed for $\mathrm{d}_{\mathrm{b}}$ values.

Individual $\mathrm{T}_{\mathrm{e}}$ values of OTMs of the same site and type (for example, all CR burrow OTMs) were averaged to calculate a mean $\mathrm{d}_{\mathrm{e}}$ value for each time of day observation(h) for each month. A repeated measures ANOVA was conducted to compare overall $d_{e}$ values of each study site and then rerun with results blocked by OTM type (burrow, intermediate, exposed) to examine differences in thermal quality among microhabitat types. Site, month, and time of day were included in both models, and significant results were followed by a Tukey-Kramer post hoc analysis.

Unfortunately, due to the unexpected early battery expiration of 21 of the snake temperature loggers in 2017, and as this was the only year in which OTMs were deployed simultaneously at all four sites along with snake body temperature loggers, our sample size was greatly reduced, and we were unable to conduct statistical comparisons of $E$ 
calculated for the remaining seven loggers as sites only yielded $n=1$ snake per all sites except MDO.

\subsection{Behavior}

In addition to the $\mathrm{T}_{\mathrm{b}}$ data collected in 2017 field season ( $\mathrm{N}=28$ snakes), behavioral data were also recorded for all radio-tagged snakes. A VHF receiver and antenna (Models TR-4K and RA-14 respectively, Telonics Telemetry-Electronics Consultants, Mesa, AZ) were used to locate radio-tagged rattlesnakes 4-5 times a week during their field active season (April-October). Tracking time and order were randomized to avoid limiting behavioral observations to any single time of day. Upon locating a snake, local environmental data were collected, and body position was recorded as either elongate, loose coil, tight coil, or "folded" ("u"-shaped). Refugium type (e.g., bush, dirt burrow, woodrat nest, etc.) was also recorded when applicable. Based on location and body position of the snake, behavior was categorized as being one of the following: in ambush, basking, hiding, resting, or transit (adapted from Beaupre, 2008; full descriptions of each behavior found in Table S3. Environmental data, including air temperature, average wind speed, and relative humidity, were captured with a handheld Kestrel Wind Meter (Model 3000, Neilsen-Kellerman Company, Boothwyn, PA, USA) near the snake. Approximate percentage of cloud cover was also recorded. GPS coordinates of the snake's location were taken with the Bad Elf 3.3.4 9 iPhone application (Bad Elf, LLC, 2011-2016). If snakes were in inaccessible terrain such as dense thickets of poison oak, or along the edges of unsafe cliffs, animal location was determined via triangulation and behavior was not recorded. Ground temperature was collected with a thermocouple (Model 14-649-81, 
Fisher Scientific, Hampton, NH, USA) in the closest similar thermal environment (e.g., separate burrows or similar substrates) to the snake's location but a safe distance removed from the strike range of the animal.

Statistical analyses of behavior were conducted with JMP v.13 software. The data used for analysis were standardized by including behavioral observations that occurred at air temperatures that occurred at all four field sites, i.e., the range was bound at the highest of the low air temperatures represented across all four field sites and the lowest high temperature. For example, if the lowest air temperatures for each of the four study sites were $5,8,9$ and $7^{\circ} \mathrm{C}$, then $9^{\circ} \mathrm{C}$ would be the lower bound for the analysis as all four sites had behavioral observations recorded at or above this temperature. This bound temperature range resulted in observations that fell between $9-31^{\circ} \mathrm{C}$ during the active season (April-October).

To address the question of whether coastal snakes had different thermoregulatory behavior frequencies than inland snakes, the behaviors were binned into "above ground" and "underground" categories. "Above ground" behaviors consisted of: transit, resting, ambush, and basking. "Underground" behavior consisted of snakes categorized as hiding. Behavioral observations were considered statistically independent of one another as a period of at least 24 hours separated each observation. We used a Chi-square analysis to compare behavior frequencies among sites and, a Bonferroni post-hoc test was performed if significance was found.

To determine if the probability of encountering a certain thermoregulatory behavior changed with air temperature among field sites, a nominal logistic fit was used to calculate and compare the behavior's probability at each site as air temperature 
increased. A generalized linear model (GLM) was then used to test if air temperature was a significant predictor of given behaviors at each site, followed by a Tukey-Kramer posthoc test. Air temperature, site and their respective interaction was included in the models.

\subsection{Energetics}

Snake field active body temperatures $\left(T_{b}\right)$ and snake morphometric data from both the historical snakes and the 2017 group $(\mathrm{N}=85)$ were used to calculate theoretical resting metabolic rates (which will be referred to as $R M R$ ). The $T_{b}$ for each individual was recorded hourly or bi-hourly with an iButton implanted within the lower third body cavity of the snake as described in the above sections. For snakes where $\mathrm{T}_{\mathrm{b}}$ was recorded bihourly, missing hourly temperatures were interpolated by taking the average of the next closest body temperatures before and after the missing hourly value. $\mathrm{T}_{\mathrm{b}}$ data were then sorted into five different time blocks (0000-0400, 0400-0800, 0800-1100, 1600-2000, 2000-0000h) based on the metabolic calculation methods established by Beaupre and Duvall (1998b), which take into account the hourly variation in rattlesnake metabolic rates base due to circadian rhythms. The hours of 1100-1600 were not included in the original literature (Beaupre \& Duvall, 1998b), so for our study we assigned temperatures from the hours of the $1100-1400$ time block to the $0800-1100$ time block and $1400-1600$ $\mathrm{h}$ to the $1600-2000$ time block. The metabolic equation established by Beaupre and Duvall is as follows:

$$
\mathrm{RMR}=\log _{10} \mathrm{VO}_{2}=\mathrm{X}_{1}+\log _{10} \text { mass }+\mathrm{X}_{2} * \text { temperature }+\mathrm{X}_{3}
$$

where " $\mathrm{X}$ " values are fitted constants established for each metabolic time block. Snake mass and field active $T_{b}$ were inputted into the appropriate equation during the aligning 
time block and the inverse log of the resulting value taken as the volume of oxygen $\left(\mathrm{ml} / \mathrm{O}_{2} /\right.$ hour) that was consumed by the individual. Oxygen consumed was then converted into individual annual energy expenditure using the standard conversion for $\mathrm{VO}_{2}$ consumed to joules $\left(19.874 \mathrm{~J} / \mathrm{ml} \mathrm{O}_{2}\right)$, which was then converted to annual caloric requirements $\left(2.39006 \times 10^{-4} \mathrm{kcal} / \mathrm{J}\right)$. We then calculated approximate the annual prey requirements of an average size male rattlesnake for each of the four study sites using their most common prey item, the California ground squirrel (Otospermophilus beecheyi; Rowe et al., 1990; Sparks et al., 2015), assuming an 80\% energetic assimilation efficiency (Secor \& Nagy, 1994) and that an average, adult ground squirrel weights approximately 500g (Evans \& Holderied, 1943) and contains roughly $690 \mathrm{kcal}$ (Kaufman, 1975; Dorcas et al, 2004).

An ANCOVA was performed to compare the daily RMR ( $\mathrm{ml} \mathrm{O}_{2} /$ day) of the four populations of snakes $(\mathrm{N}=85)$ during their active season (April-Oct). Snake mass, site, and the site $\mathrm{x}$ mass interaction were included in the model. We assumed mass to be a significant predictor, as it was used to calculate metabolic rates, however, it was included in the model account for any variation associated with snake size. Significant findings were followed by a Tukey-Kramer post hoc analysis.

\subsection{Climate Change Projections}

In order to estimate the changes in habitat thermal quality and therefore energetic consequences of anthropogenic climate change on snakes, we used Cal-Adapt's (2019) representative concentration pathway (RCP) climate scenario 4.5 as a "best case" scenario in which emissions peak around the year 2040, then steadily decline. Using the 
"modeled projected annual mean" tool, we identified the years in which the annual average temperatures had increased one degree from the 2017 average for each of the four study sites $(\mathrm{CR} / \mathrm{SG} / \mathrm{VAFB}=2030, \mathrm{MDO}=2047)$. We repeated this procedure for a two-degree increase as well. To make predictions, we then assumed that $1{ }^{\circ} \mathrm{C}$ increase in annual average temperature would be equivalent to an equivalent increase in $\mathrm{T}_{\mathrm{e}}$ of all microhabitats. We calculated the proportion of current mean $\mathrm{T}_{\mathrm{e}}$ for each site and habitat type that fell within $\mathrm{T}_{\text {set }}$ for 2017 as well as the change in that proportion for both $1{ }^{\circ} \mathrm{C}$ and $2{ }^{\circ} \mathrm{C}$ increases. Additionally, we calculated the change in mean $\mathrm{d}_{\mathrm{e}}$ for each site and microhabitat type. Lastly, we calculated the mean increase in annual energetic needs (kcal/year) by adding $1{ }^{\circ} \mathrm{C}$ and $2{ }^{\circ} \mathrm{C}$ to the mean hourly $\mathrm{T}_{\mathrm{b}}$ of each snake and using the Beaupre and Duvall (1998b) equation to recalculate mean RMR for each of the four sites. Differences in current, $1^{\circ} \mathrm{C}$, and $2{ }^{\circ} \mathrm{C}$ increases were then compared using a repeatedmeasures ANOVA, with site included as a factor. 


\section{Results:}

\subsection{Preferred Body Temperature $\left(T_{\text {set }}\right)$}

The mean median $\mathrm{T}_{\text {set }}$ of all snakes $(\mathrm{N}=45)$ was $29.22 \pm 0.92{ }^{\circ} \mathrm{C}$ with a $50 \%$ interquartile range of $26.3 \pm 1.01^{\circ} \mathrm{C}-32.3 \pm 0.84^{\circ} \mathrm{C}$ (Blouin-Demers \& Weatherhead, 2001). None of the factors tested (site, sex, mass, season, or presence of internal radio transmitter; Charland, 1990) significantly affected median $\mathrm{T}_{\text {set }}\left(\mathrm{F}_{8.36}=1.30, \mathrm{p}=0.27\right.$; Figure S1).

\subsection{Field Active Body Temperature $\left(T_{b}\right)$}

A total of 256,683 individual snake $(\mathrm{N}=85) \mathrm{T}_{\mathrm{b}}$ data points were collected during the active season (Apr-Oct) from the years 2010-2017. After accounting for monthly and diel variations in temperature, we found that $T_{b}$ was significantly different among sites, with snakes from both $\mathrm{CR}$ and $\mathrm{SG}$ sites having higher mean body temperatures than snakes from both MDO and VAFB sites $\left(\mathrm{F}_{3,83.2}=26.16, \mathrm{p}<0.0001\right)$. A Tukey-Kramer post-hoc test showed no significant differences between $T_{b}$ within coastal or inland populations (Figure 2). 


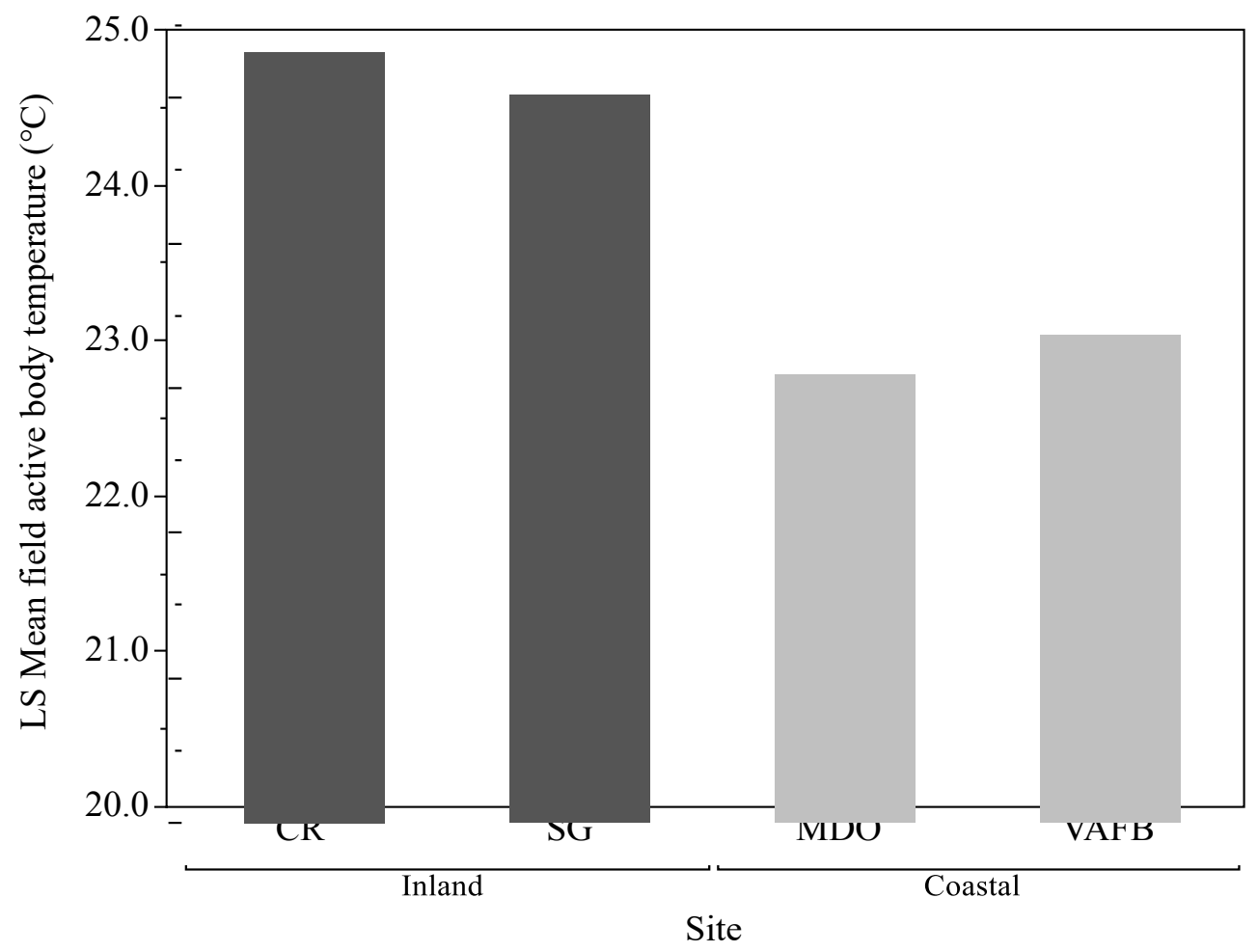

Figure 2. Least squares (LS) mean hourly field active body temperatures $\left(\mathrm{T}_{\mathrm{b}}\right)$ for four populations of $C$. oreganus $(\mathrm{N}=85 ; \mathrm{CR}=23, \mathrm{SG}=28, \mathrm{MDO}=15, \mathrm{VAFB}=19)$ on the Central Coast of California during the active season (April-Oct). Mean body temperatures differed significantly among sites, with Sedgwick having the highest mean body temperatures and Montaña de Oro with the lowest. A Tukey-Kramer post-hoc test showed no significant differences between $T_{b}$ within coastal or inland populations. Different letters represent a significant difference between means and bars represent $95 \%$ confidence intervals.

\subsection{Operative Temperatures $\left(T_{e}\right)$}

A total of 112,083 individual OTM temperatures ( $\mathrm{n}=5$ OTMs/site) were recorded over a one year period from June 2017-June 2018. After accounting for monthly and diel variations in temperature, we found that mean monthly $\mathrm{T}_{\mathrm{e}}$ was significantly different among sites $\left(\mathrm{F}_{11}=366.18, \mathrm{p}<0.0001\right.$; Figure 3$)$ but overall mean annual site $\mathrm{T}_{\mathrm{e}}(17.16 \pm$ $\left.1.23^{\circ} \mathrm{C}\right)$ was not $\left(\mathrm{F}_{3}=0.41, \mathrm{p}=0.75\right)$. 


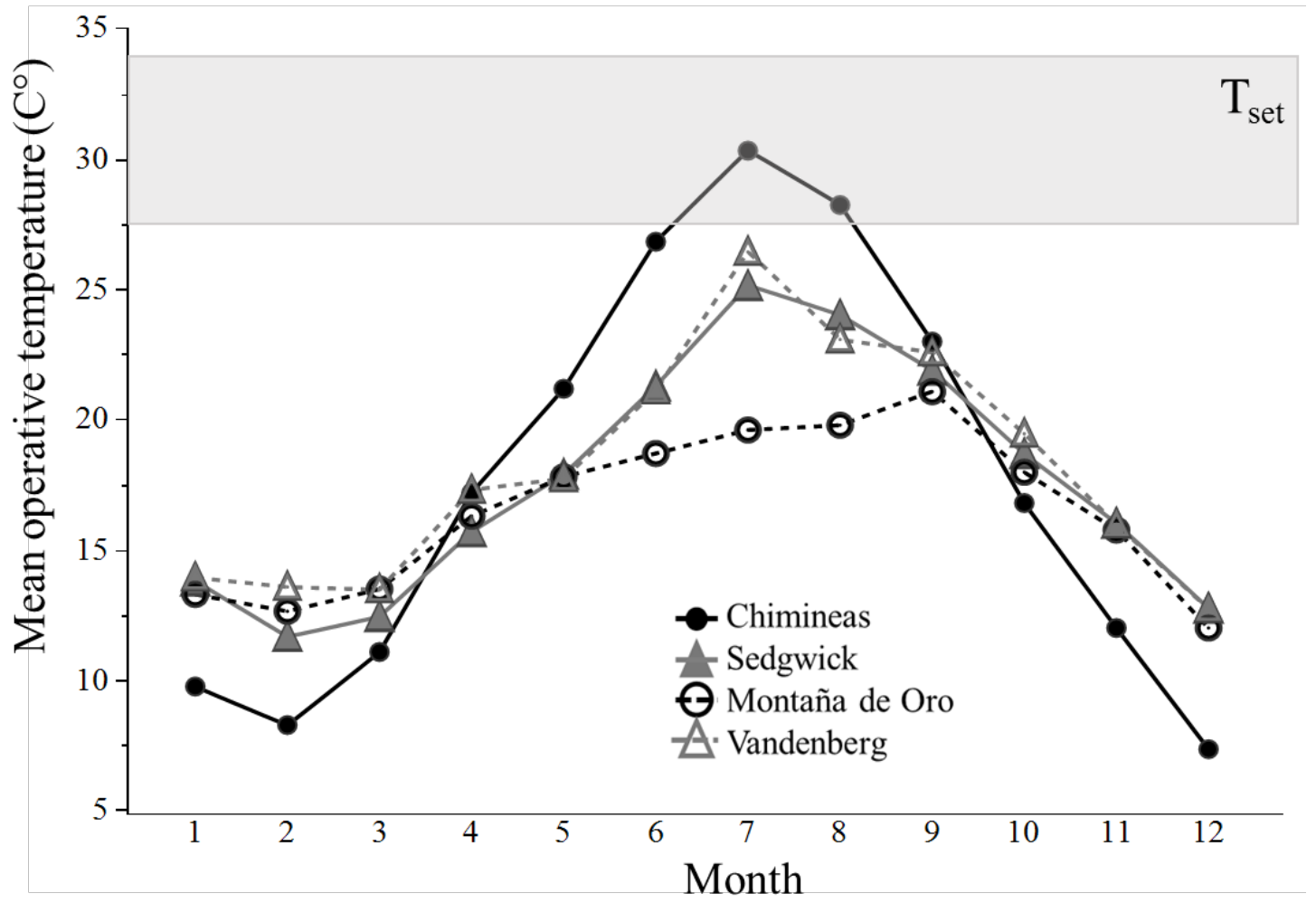

Figure 3: Mean monthly operative temperatures $\left(T_{e}\right)$ for each of the four study sites on the Central Coast of California. Mean monthly $\mathrm{T}_{\mathrm{e}}$ differed significantly among sites but mean overall annual $\mathrm{T}_{\mathrm{e}}$ did not. SG mean temperatures reported here are lower than actual expected site values due to the continuous failure of exposed OTMs in extreme summer temperatures. Grey bar represents the preferred body temperature range $\left(\mathrm{T}_{\mathrm{set}}\right)$ of Crotalus oreganus.

\subsection{Thermal Quality $\left(d_{e}\right)$}

A total of 3,048 mean hourly $\mathrm{d}_{\mathrm{e}}$ values we obtained from all OTMs (n=5/site) at all sites. There was a significant difference in $\mathrm{d}_{\mathrm{e}}$ among study sites; post-hoc analysis showed no significant difference in overall mean $\mathrm{d}_{\mathrm{e}}$ among the two coastal sites (MDO \& VAFB) and SG but did show that mean $C R d_{e}$ was significantly higher than all other sites (Table 2). All interaction terms within the model proved to be significant (Table 3).

When the same test was run with $d_{e}$ values blocked by OTM type, there was still a significant difference in $\mathrm{d}_{\mathrm{e}}$ among sites within each OTM type (Burrow, $\mathrm{F}_{3}=143.15$, $\mathrm{p}<0.0001$; Intermediate, $\mathrm{F}_{2}=75.13, \mathrm{p}<0.0001 ;$ Exposed, $\mathrm{F}_{2}=19.38, \mathrm{p}<0.0001 ;$ Table 2). 
Because of the failure of SG exposed OTMs, no exposed $d_{e}$ values were included for the overall calculations for $\mathrm{SG}$, therefore resulting in a lower overall $\mathrm{d}_{\mathrm{e}}$ value than the actual value and reducing the SG OTM sample size to $\mathrm{n}=3$. Due to similar overall climates and location, we expect that $\mathrm{SG} \mathrm{d}_{\mathrm{e}}$ values would have been similar to $\mathrm{CR}$.

Table 2: Operative temperatures $\left(T_{e}\right)$ and thermal quality $\left(d_{e}\right)$ values for each OTM type at each of the four study sites from June 2017 to June 2018. Thermal quality values closer to zero are indicative of better thermal quality. Different letters indicate significant differences among OTMs of the same type. *Mean $d_{\mathrm{e}}$ for SG does not include exposed OTM values, as all exposed SG OTMs failed; therefore, mean $d_{e}$ is lower than would be expected if exposed values were included. Values followed by \pm 1 SEM.

\begin{tabular}{|c|c|c|c|c|c|c|c|}
\hline Site & OTM Type & $\begin{array}{c}\text { Mean } T_{e} \\
(\rho C)\end{array}$ & $\begin{array}{c}\operatorname{Min} T_{e} \\
(\rho C)\end{array}$ & $\begin{array}{c}\operatorname{Max} T_{e} \\
(\rho C)\end{array}$ & Mean de & $\begin{array}{c}\operatorname{Max} \\
d_{e}\end{array}$ & Overall Site de \\
\hline \multirow{3}{*}{$\begin{array}{l}\text { CR } \\
\text { (Inland) }\end{array}$} & Burrow & $14.91 \pm 7.03$ & -0.95 & 31.11 & $11.18 \pm 0.11^{\mathrm{a}}$ & 27.25 & \multirow{3}{*}{$13.21 \pm 0.16^{\mathrm{a}}$} \\
\hline & Intermediate & $13.56 \pm 11.45$ & -5.02 & 56.98 & $14.80 \pm 0.27^{\mathrm{a}}$ & 31.32 & \\
\hline & Exposed & $19.62 \pm 16.51$ & -10.54 & 70.37 & $14.16 \pm 0.30^{\mathrm{a}}$ & 38.07 & \\
\hline \multirow{3}{*}{$\begin{array}{l}\text { SG } \\
\text { (Inland) }\end{array}$} & Burrow & $17.79 \pm 4.13$ & 1.53 & 31.13 & $8.55 \pm 0.11^{\mathrm{c}}$ & 24.77 & \multirow{3}{*}{$10.59 \pm 0.17^{\mathrm{b} *}$} \\
\hline & Intermediate & $17.24 \pm 12.67$ & -4.00 & 55.99 & $12.59 \pm 0.19^{b}$ & 30.30 & \\
\hline & Exposed & - & - & - & - & - & \\
\hline \multirow{3}{*}{$\begin{array}{l}\text { MDO } \\
\text { (Coastal) }\end{array}$} & Burrow & $14.38 \pm 3.36$ & 6.58 & 26.62 & $11.48 \pm 0.11^{\mathrm{a}}$ & 19.72 & \multirow{3}{*}{$11.10 \pm 0.14^{\mathrm{b}}$} \\
\hline & Intermediate & $15.46 \pm 5.19$ & 3.54 & 41.56 & $10.96 \pm 0.19^{c}$ & 22.76 & \\
\hline & Exposed & $19.07 \pm 11.06$ & -5.25 & 56.51 & $10.91 \pm 0.30^{\mathrm{b}}$ & 31.55 & \\
\hline \multirow{3}{*}{$\begin{array}{l}\text { VAFB } \\
\text { (Coastal) }\end{array}$} & Burrow & $16.55 \pm 4.22$ & 7.06 & 34.58 & $9.70 \pm 0.11^{\mathrm{b}}$ & 19.24 & \multirow{3}{*}{$11.11 \pm 0.14^{\mathrm{b}}$} \\
\hline & Intermediate & $16.53 \pm 10.45$ & -12.62 & 58.93 & $12.08 \pm 0.19^{b}$ & 38.92 & \\
\hline & Exposed & $20.55 \pm 13.34$ & -2.48 & 63.44 & $11.46 \pm 0.30^{\mathrm{b}}$ & 31.14 & \\
\hline
\end{tabular}


Table 3: Summary results of the repeated-measures ANOVA for the effects of site, month, and time of day on overall mean $\mathrm{d}_{\mathrm{e}}$ of four field sites occupied by four distinct populations of Crotalus oreganus on the Central Coast of California.

\begin{tabular}{lccc}
\hline \multicolumn{1}{c}{ Predictor } & $\boldsymbol{F}$ & $\boldsymbol{d f}$ & $\boldsymbol{P}$ \\
\hline Site & 31.29 & 3 & $<0.0001^{*}$ \\
Month & 121.67 & 11 & $<0.0001^{*}$ \\
Time & 64.14 & 23 & $<0.0001^{*}$ \\
Month*Time & 2.56 & 253 & $<0.0001^{*}$ \\
Month*Site & 4.98 & 33 & $<0.0001^{*}$ \\
Time*Site & 0.83 & 69 & 0.84 \\
Month*Time*Site & 0.33 & 759 & 1.00 \\
\hline
\end{tabular}

\subsection{Thermoregulatory Accuracy $\left(d_{b}\right)$}

Using the same model approach and adjustments as was used for our $\mathrm{T}_{\mathrm{b}}$ analysis, we found significant differences in thermoregulatory accuracy $\left(\mathrm{d}_{\mathrm{b}}\right)$ among study sites, with inland snakes $(\mathrm{CR}, \mathrm{SG})$ being more accurate thermoregulators than coastal snakes $\left(\mathrm{MDO}, \mathrm{VAFB} ; \mathrm{F}_{3,84.4}=37.17, \mathrm{p}<0.0001 ;\right.$ Figure 4$)$. This resulted from snakes at both $\mathrm{CR}$ and SG spending an overall larger portion of time in or near preferred body temperatures throughout the entirety of the study (Figure 5). On average, $50.89 \%$ of hourly $\mathrm{T}_{\mathrm{b}}$ observations fell within the $\mathrm{T}_{\text {set }}$ for inland snakes while only $21.63 \%$ fell within for coastal snakes. A Tukey-Kramer post-hoc adjustment revealed no significant differences between inland sites or between coastal sites (Figure 4). 


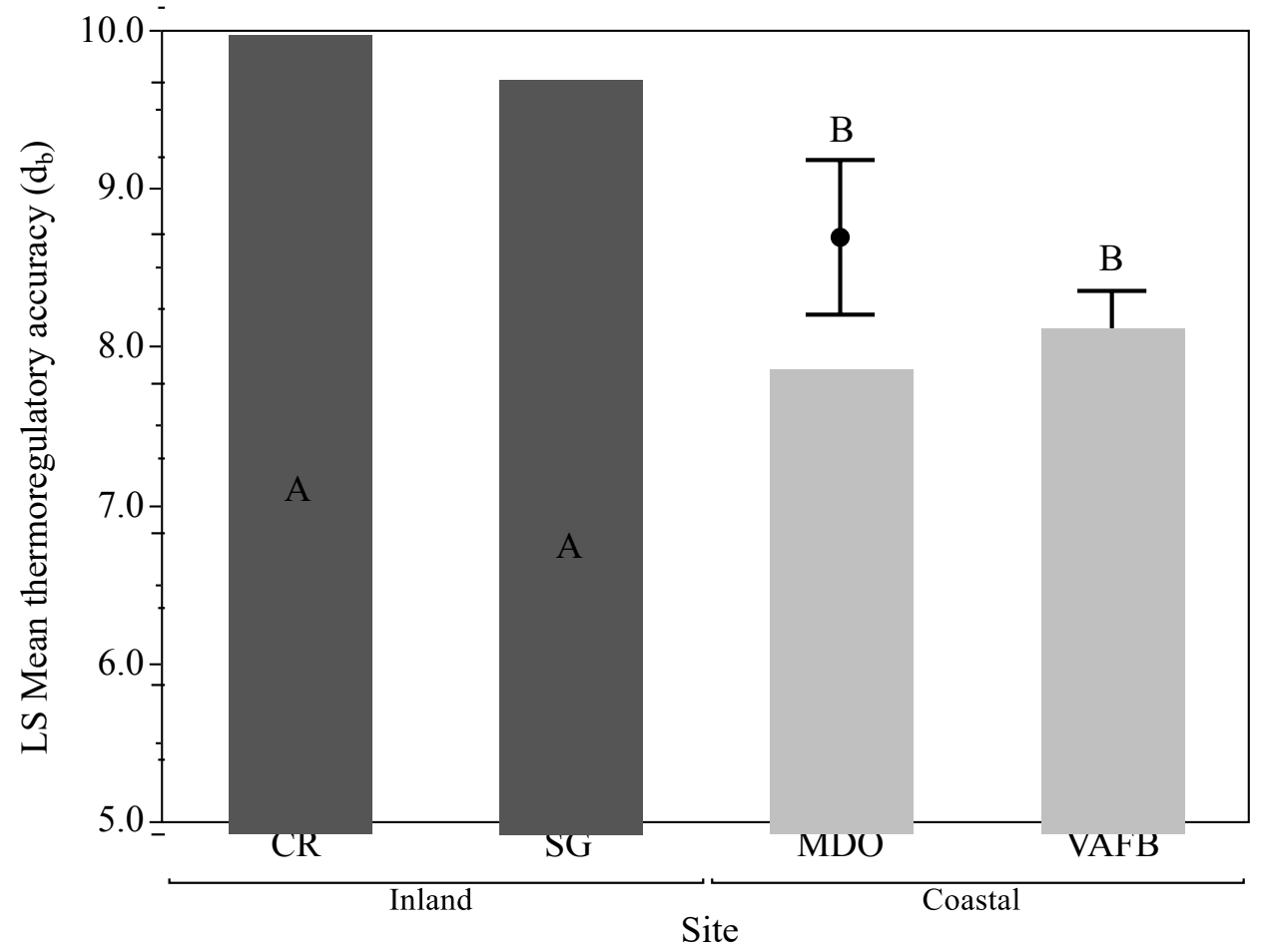

Figure 4: Mean thermoregulatory accuracy $\left(\mathrm{d}_{\mathrm{b}}\right)$ for each of the four populations of $C$. oreganus $(\mathrm{N}=85, \mathrm{CR}=23, \mathrm{SG}=28, \mathrm{MDO}=15, \mathrm{VAFB}=19)$ on the Central Coast of California. Values closer to zero mean higher thermal accuracy. Mean daily $\mathrm{d}_{\mathrm{b}}$ differed significantly among sites, with inland snakes (CR, SG) thermoregulating more accurately than coastal snakes (MDO, VAFB). A Tukey-Kramer post-hoc test revealed that inland sites did not significantly differ from one another, nor did coastal sites. Different letters represent a significant difference between means and bars represent $95 \%$ confidence intervals. 


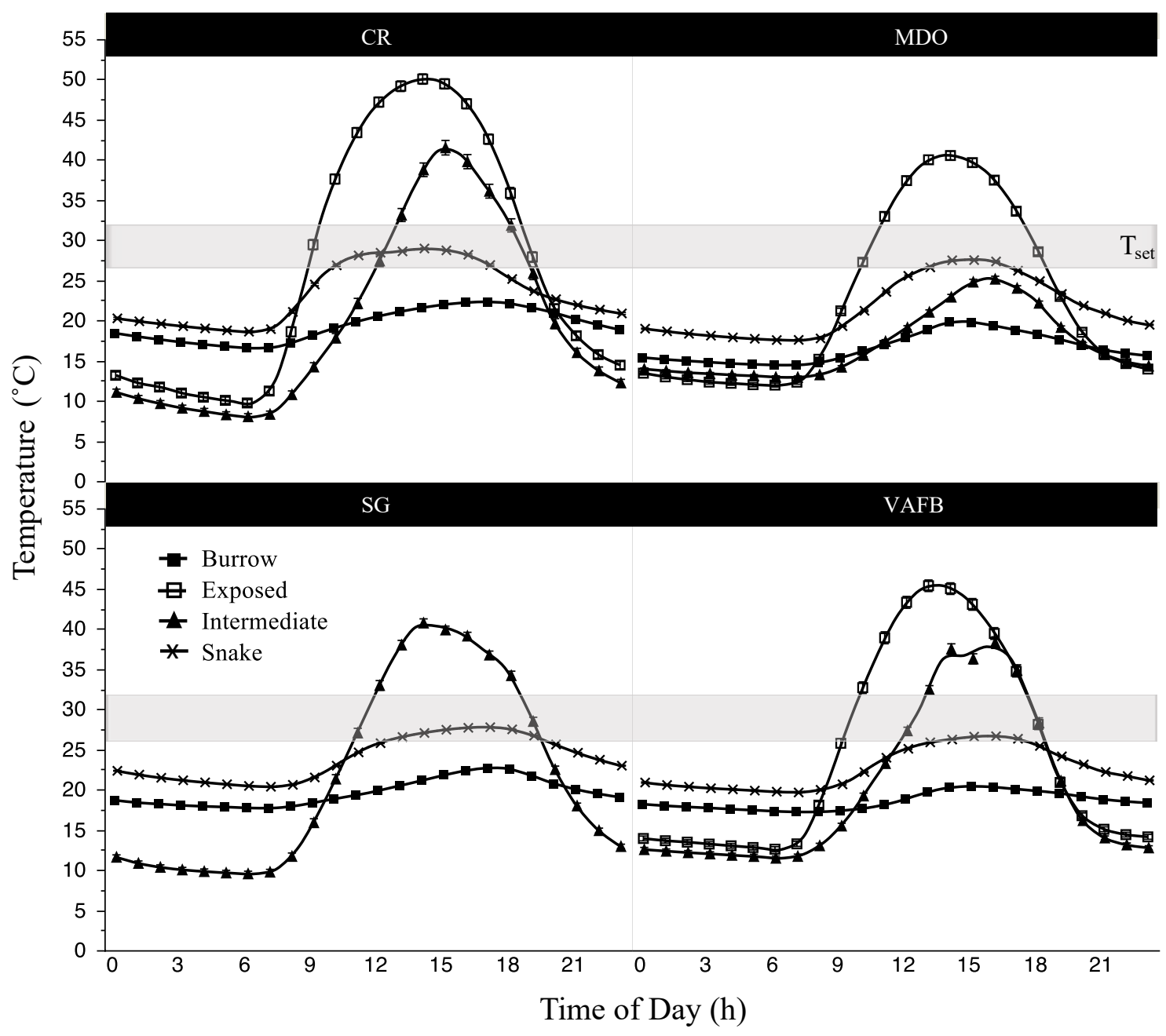

Figure 5. Mean hourly operative and Crotalus oreganus body temperatures over the duration of the active season (Apr-Oct) for each of the four study sites (CR, SG, MDO, VAFB) on the Central Coast of California. CR and SG are inland sites and MDO and VAFB are coastal sites. Grey bars represent the preferred body temperature range $\left(\mathrm{T}_{\mathrm{set}}\right)$ of $C$. oreganus.

\subsection{Thermoregulatory Effectiveness (E)}

Raw values suggest that $\mathrm{CR}$ snakes thermoregulate most effectively of all populations in intermediate and exposed microhabitat as well as overall. Comparatively, snakes at MDO thermoregulate least effectively of all populations in intermediate and exposed microhabitats as well as overall. Again, due to the failure of exposed OTMs at SG, we do not have an exposed $\mathrm{E}$ value for this site; however, we would again expect this value to be comparable to that of CR's snakes due to similarities in climate (Table 4). 
Table 4. Mean indices of thermoregulatory effectiveness $(E)$ for the 2017 Crotalus oreganus active season (Apr-Oct). *Actual SG overall site mean $E$ is likely higher than reported and similar to that of the other inland site, CR. Exposed SG OTM continuously failed in the extreme daytime temperatures.

\begin{tabular}{lccccc}
\hline \multicolumn{1}{c}{ Site } & $\boldsymbol{n}$ & $\begin{array}{c}\text { Mean Burrow } \\
\boldsymbol{E}\end{array}$ & $\begin{array}{c}\text { Mean Intermediate } \\
\boldsymbol{E}\end{array}$ & $\begin{array}{c}\text { Mean Exposed } \\
\boldsymbol{E}\end{array}$ & $\begin{array}{c}\text { Overall Site } \\
\boldsymbol{E}\end{array}$ \\
\hline CR (Inland) & 1 & 0.60 & 0.74 & 0.77 & 0.72 \\
SG (Inland) & 1 & 0.50 & 0.68 & - & $0.62^{*}$ \\
MDO (Coastal) & 4 & 0.59 & 0.58 & 0.58 & 0.58 \\
VAFB (Coastal) & 1 & 0.64 & 0.72 & 0.74 & 0.71 \\
\hline
\end{tabular}

\subsection{Behavior}

We recorded a total of 1141 behavioral observations $(\mathrm{CR}=226, \mathrm{SG}=258, \mathrm{MDO}$ $=393, \mathrm{VAFB}=264)$ of $C$. oreganus during the 2017 active season $(\mathrm{N}=28$ snakes $)$. When compared to all other field sites, snakes at MDO hid less frequently than snakes at the other field sites $\left(\chi^{2}=38.40, \mathrm{df}=3, \mathrm{p}<0.0001\right.$; Figure 6$)$, whereas the CR rattlesnakes hid more frequently than snakes at the other field sites $\left(\chi^{2}=25.90, \mathrm{df}=3, \mathrm{p}<0.0001\right)$. Snakes at MDO and SG were observed basking significantly more often than snakes at VB and CR (Figure 6). Frequency of hiding observations varied significantly among all four sites except for SG, which was not different from MDO or VAFB. CR snakes showed the highest proportion of hiding behavior observations whereas MDO snakes showed the lowest. 


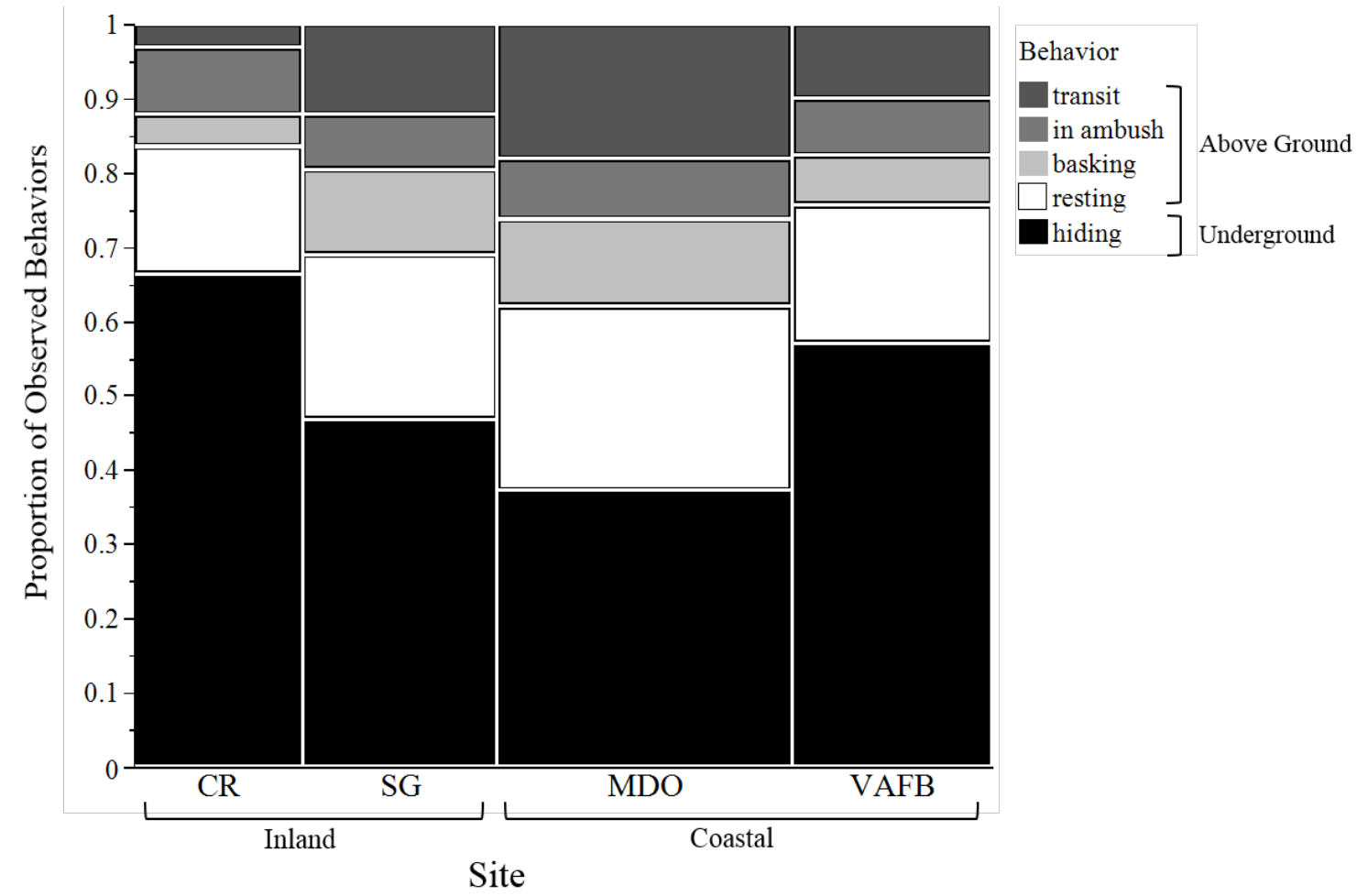

Figure 6. Proportion of observed behaviors $(\mathrm{N}=1141)$ for four populations of Crotalus oreganus $(\mathrm{N}=85$ snakes; $\mathrm{CR}=23, \mathrm{SG}=28, \mathrm{MDO}=15, \mathrm{VAFB}=19)$ on the Central Coast of California during the active season (April-October 2017). Snakes at CR (hotter conditions) were hiding more frequently when compared to all other sites and snakes at MDO (mild conditions) were hiding less frequently when compared to all other sites. Column widths reflect the number of behavioral observations per site.

Significant interactions were found between site and air temperature for ambush $\left(\mathrm{n}=91, \chi^{2}=9.99, \mathrm{df}=3, \mathrm{p}=0.02\right)$ and transit $\left(\mathrm{n}=135, \chi^{2}=9.70, \mathrm{df}=3, \mathrm{p}=0.02\right)$, but not for basking $\left(\mathrm{n}=104, \chi^{2}=5.45, \mathrm{df}=3, \mathrm{p}=0.14\right)$, hiding $\left(\mathrm{n}=569, \chi^{2}=6.51, \mathrm{df}=3, \mathrm{p}\right.$ $=0.09)$, or resting $\left(\mathrm{n}=242, \chi^{2}=6.98, \mathrm{df}=3, \mathrm{p}=0.07\right.$; Figure 7), meaning that the likelihood of observing a snake in ambush or transit at a given site can be accurately predicted at a given air temperature. Additionally, field site alone was also a significant predictor for the behaviors of basking and hiding $\left(\chi^{2}=16.50, \mathrm{df}=3, \mathrm{p}<0.0009\right.$, and $\chi^{2}=$ $42.80, \mathrm{df}=3, \mathrm{p}<0.0001$ respectively). Basking was negatively correlated with air temperature at all sites except for $\mathrm{CR}$ while hiding was negatively correlated with air 
temperature at VAFB and positively correlated at all other sites. However, the positive correlation with air temperature only occurred until roughly $25^{\circ} \mathrm{C}$, after which the correlation became negative at all four sites.

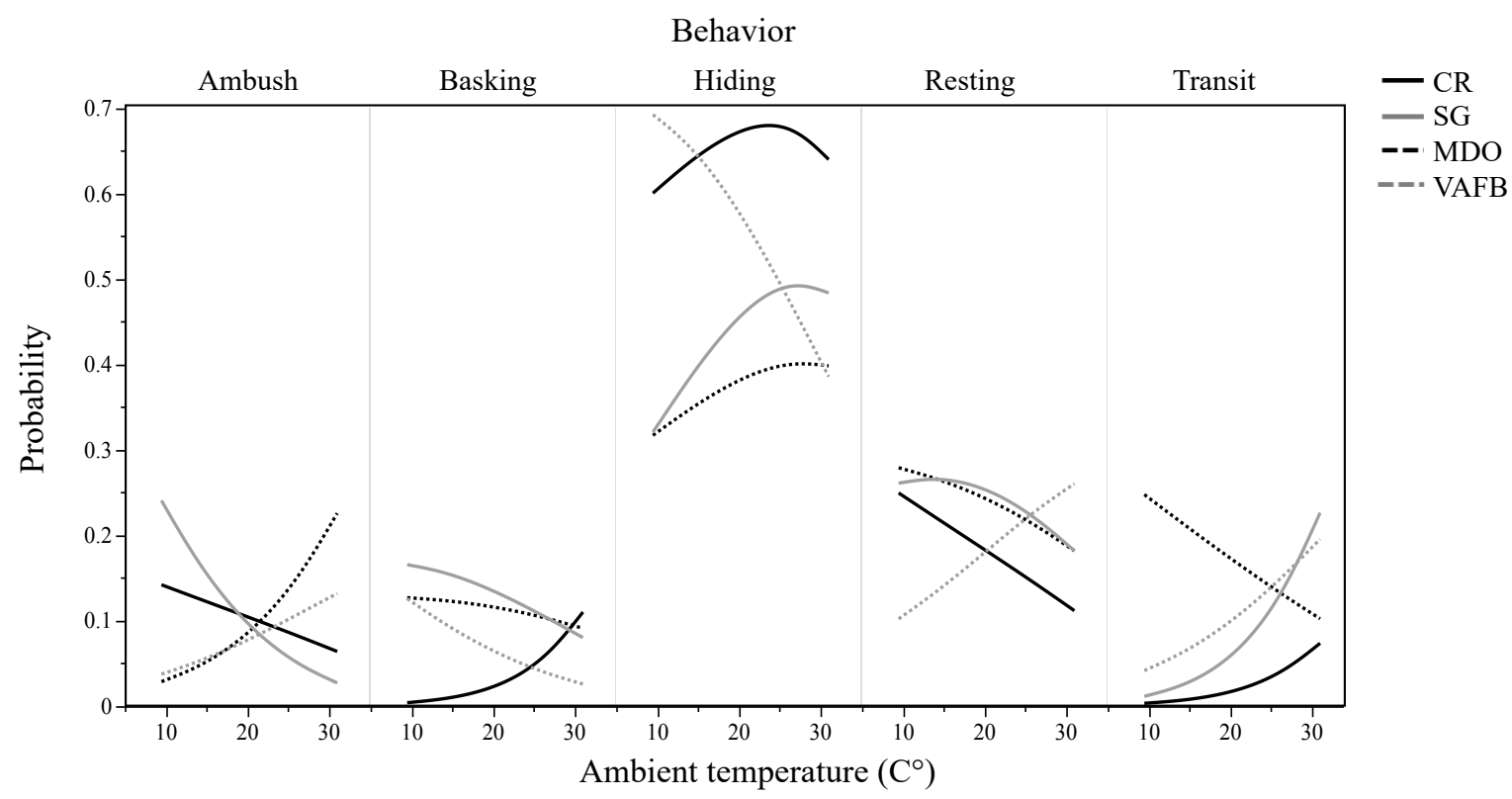

Figure 7. Probability predictions for observing Crotalus oreganus $(\mathrm{N}=85$ snakes; $\mathrm{CR}=23, \mathrm{SG}=$ $28, \mathrm{MDO}=15, \mathrm{VAFB}=19)$ behaviors across a range of ecologically relevant air temperatures (9$31{ }^{\circ} \mathrm{C}$ ) for four distinct populations on the Central Coast of California. CR and SG represent inland populations and MDO and VAFB represent coastal populations. Air temperature was a significant predictor for ambush and transit behaviors but not for basking, hiding, or resting. Field site was a significant predictor for basking and hiding but not for ambush, resting, or transit behaviors.

\subsection{Energetics}

The daily RMR of snakes across all four study sites differed significantly, with inland snakes $(\mathrm{CR}, \mathrm{SG})$ having higher overall RMR than coastal (MDO, VAFB) snakes $\left(F_{7,77}=136.68, p<0.0001\right.$, Figure $\left.8 a\right)$. Both site $\left(F_{3}=7.57, p<0.0002\right)$ and snake mass $\left(F_{1}\right.$ $=192.82, \mathrm{p}<0.0001)$ were significant predictors of daily RMR, but not the interaction between them. A Tukey's post-hoc test revealed no significant difference between the 
RMR of snakes from similar site types (i.e., coastal and inland). When corrected for mass (by dividing overall values by the raw mass of the snake), there was no significant difference in snake RMR across all sites $\left(\mathrm{F}_{3,81}=1.50, \mathrm{p}=0.22\right.$; Figure $\left.8 \mathrm{~b}\right)$.

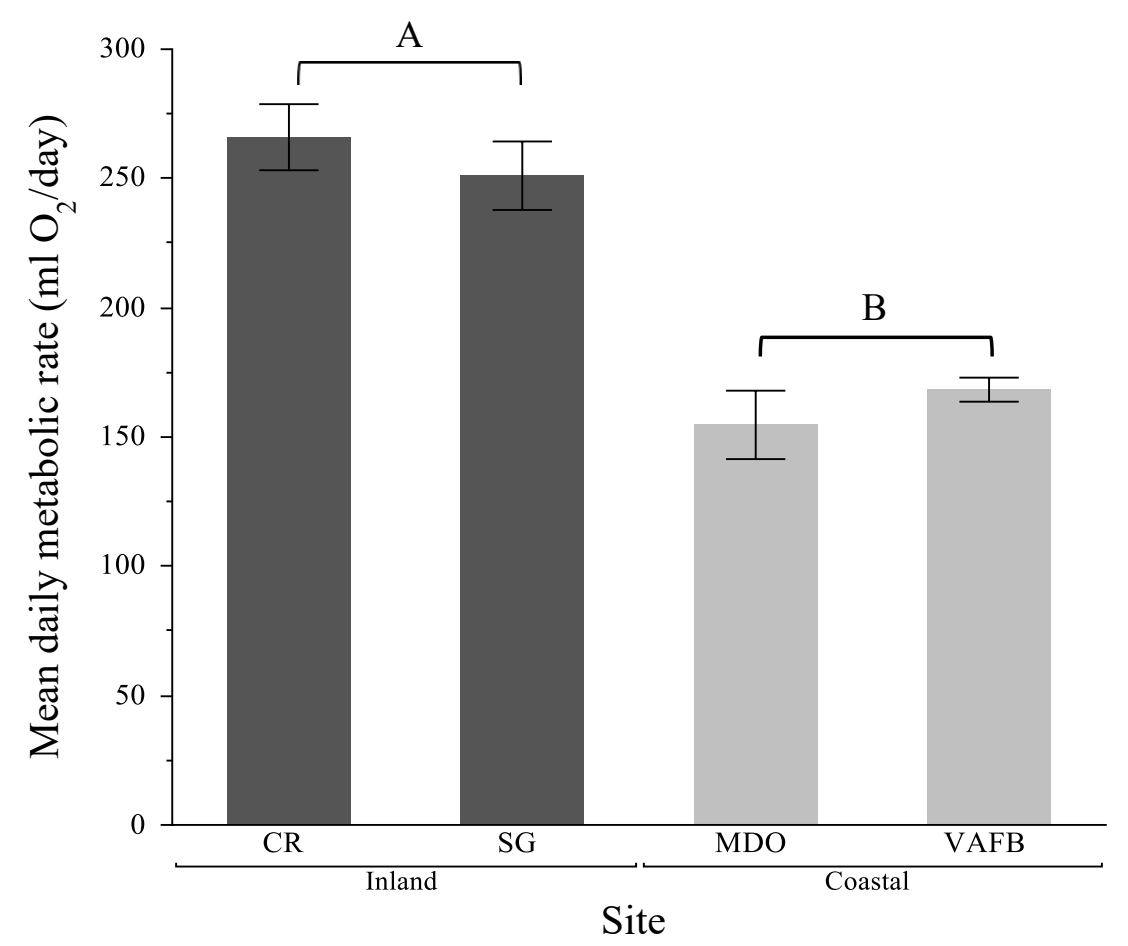

Figure 8a. Mean daily resting metabolic rates $\left(\mathrm{ml} \mathrm{O}_{2} /\right.$ day) of adult, male $C$. oreganus $(\mathrm{N}=85 ; \mathrm{CR}$ $=23, \mathrm{SG}=28, \mathrm{MDO}=15, \mathrm{VAFB}=19$ ) from four different populations (two inland, two coastal) in Central California (based on established metabolic equations from Beaupre \& Duvall, 1998). Snakes from inland sites have significantly higher metabolic rates than snakes from coastal sites. Different letters represent a significant difference between means and standard error bars represent \pm 1 SEM. 


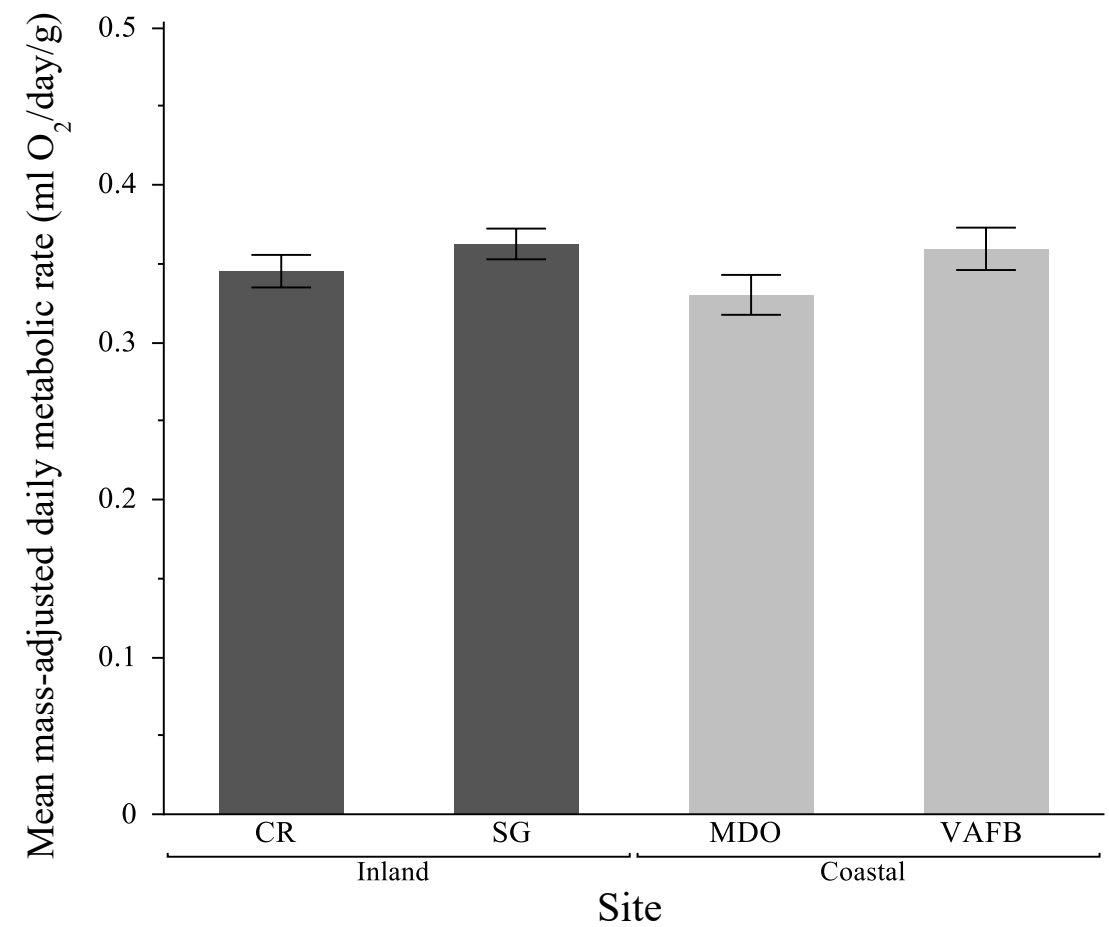

Figure 8b. Mass-specific daily resting metabolic rates $\left(\mathrm{ml} \mathrm{O}_{2} /\right.$ day $\left./ \mathrm{g}\right)$ of adult, male $C$. oreganus $(\mathrm{N}=85$ snakes; $\mathrm{CR}=23, \mathrm{SG}=28, \mathrm{MDO}=15, \mathrm{VAFB}=19)$ from four different populations $(2$ inland, 2 coastal) in Central California (based on established metabolic equations from Beaupre \& Duvall, 1998). There was no significant difference among the mass-corrected metabolic rates at any of the sites. Standard error bars represent \pm 1 SEM.

When mean RMR values were converted to annual energetic needs we found that an individual snakes from all four of the snake populations needed to eat less than the equivalent of one adult ground squirrel per year in order to maintain RMRs. An average, adult male inland snake would need to consume a mean of 0.80 ground squirrels a year whereas a coastal snake would need an average of 0.51 squirrels per year (Figure 9). 


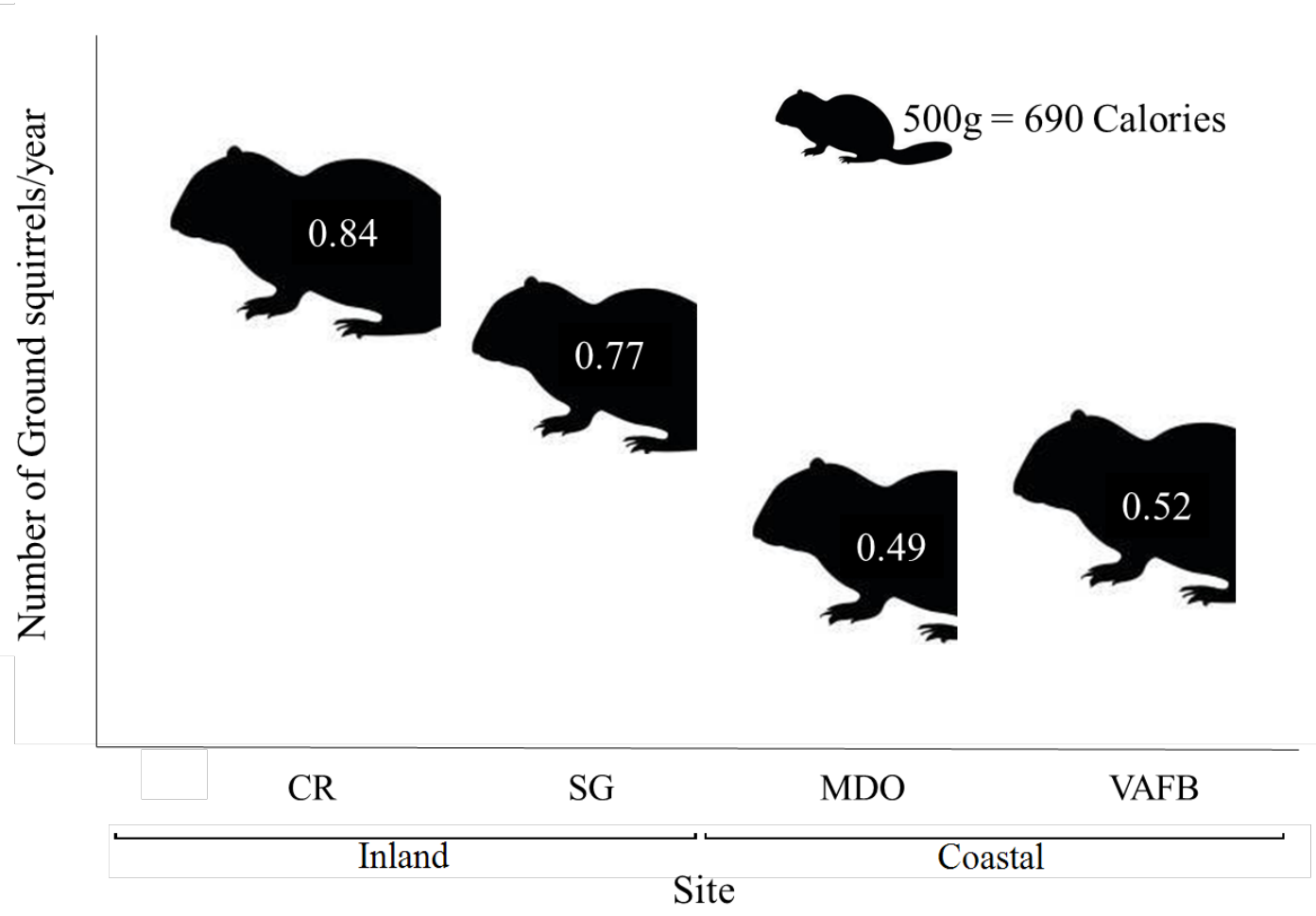

Figure 9. Number of ground squirrels (Otospermophilus beecheyi) an average, adult male Crotalus oreganus from four distinct populations on the Central Coast of California (CR, SG, $\mathrm{MDO}, \mathrm{VAFB}$ ) would need to consume in order to meet annual baseline energetic requirements.

\subsection{Climate Change Projections}

During the period that OTMs were deployed (June 2017-June 2018), the overall proportion of hourly $\mathrm{T}_{\mathrm{e}}$ that fell below the C. oreganus $\mathrm{T}_{\text {set }}$ was considerably higher (0.856) than the proportion that fell within $(0.056)$ or above $(0.085)$ this range. While these proportions varied among and within each site and microhabitat type (Table 5), this general trend held true across all categories. 
Table 5. Proportion of hourly operative temperatures from June 2017 to June 2018, across four sites on the Central California Coast, that fall within the interquartile $\mathrm{T}_{\text {set }}$ range of $C$. oreganus with a $1{ }^{\circ} \mathrm{C}$ and $2{ }^{\circ} \mathrm{C}$ increase in ambient temperature. Also note the year in which these temperature increases are expected to occur varies from site to site. Years were extrapolated using the most conservative RCP model (4.5).

\begin{tabular}{llccc}
\hline \multicolumn{1}{c}{ Site } & \multicolumn{1}{c}{$\begin{array}{c}\text { OTM } \\
\text { Habitat }\end{array}$} & $\begin{array}{c}\text { Current (2017) Prop. of } \\
\text { Temps within } \text { set }\end{array}$ & $\begin{array}{c}\mathbf{1}^{\circ} \mathrm{C} \text { increase (year } \\
\text { expected) }\end{array}$ & $\begin{array}{c}2^{\circ} \mathrm{C} \text { increase (year } \\
\text { expected) }\end{array}$ \\
\hline CR & Burrow & 0.07 & $0.11(2030)$ & $0.14(2052)$ \\
(Inland) & Intermediate & 0.05 & $0.06(2030)$ & $0.06(2052)$ \\
& Exposed & 0.07 & $0.09(2030)$ & $0.09(2052)$ \\
SG & Burrow & 0.03 & $0.05(2030)$ & $0.07(2050)$ \\
(Inland) & Intermediate & 0.08 & $0.08(2030)$ & $0.09(2050)$ \\
& Exposed & - & - & - \\
MDO & Burrow & 0.00 & $0.00(2047)$ & $0.00(2055)$ \\
$($ Coastal) & Intermediate & 0.03 & $0.04(2047)$ & $0.05(2055)$ \\
& Exposed & 0.10 & $0.10(2047)$ & $0.10(2055)$ \\
VAFB & Burrow & 0.02 & $0.04(2030)$ & $0.06(2053)$ \\
(Coastal) & Intermediate & 0.07 & $0.07(2030)$ & $0.08(2053)$ \\
& Exposed & 0.08 & $0.08(2030)$ & $0.08(2053)$ \\
\hline
\end{tabular}

With a $1{ }^{\circ} \mathrm{C}$ increase in $\mathrm{T}_{\mathrm{e}}$, the overall mean proportion of hourly temperatures that falls within $\mathrm{T}_{\text {set }}$ increased to 0.064 , with still the majority of hourly readings falling below $\mathrm{T}_{\text {set }}(0.084)$ and 0.091 falling above. A $2{ }^{\circ} \mathrm{C}$ increase shows the same pattern, with a higher proportion of $\mathrm{T}_{\mathrm{e}}$ falling within the $\mathrm{T}_{\text {set }}$ range $(0.075)$, the proportion below $\mathrm{T}_{\text {set }}$ decreasing (0.825), and the proportion above $\mathrm{T}_{\text {set }}$ increasing $(0.096$, Figure 10). 


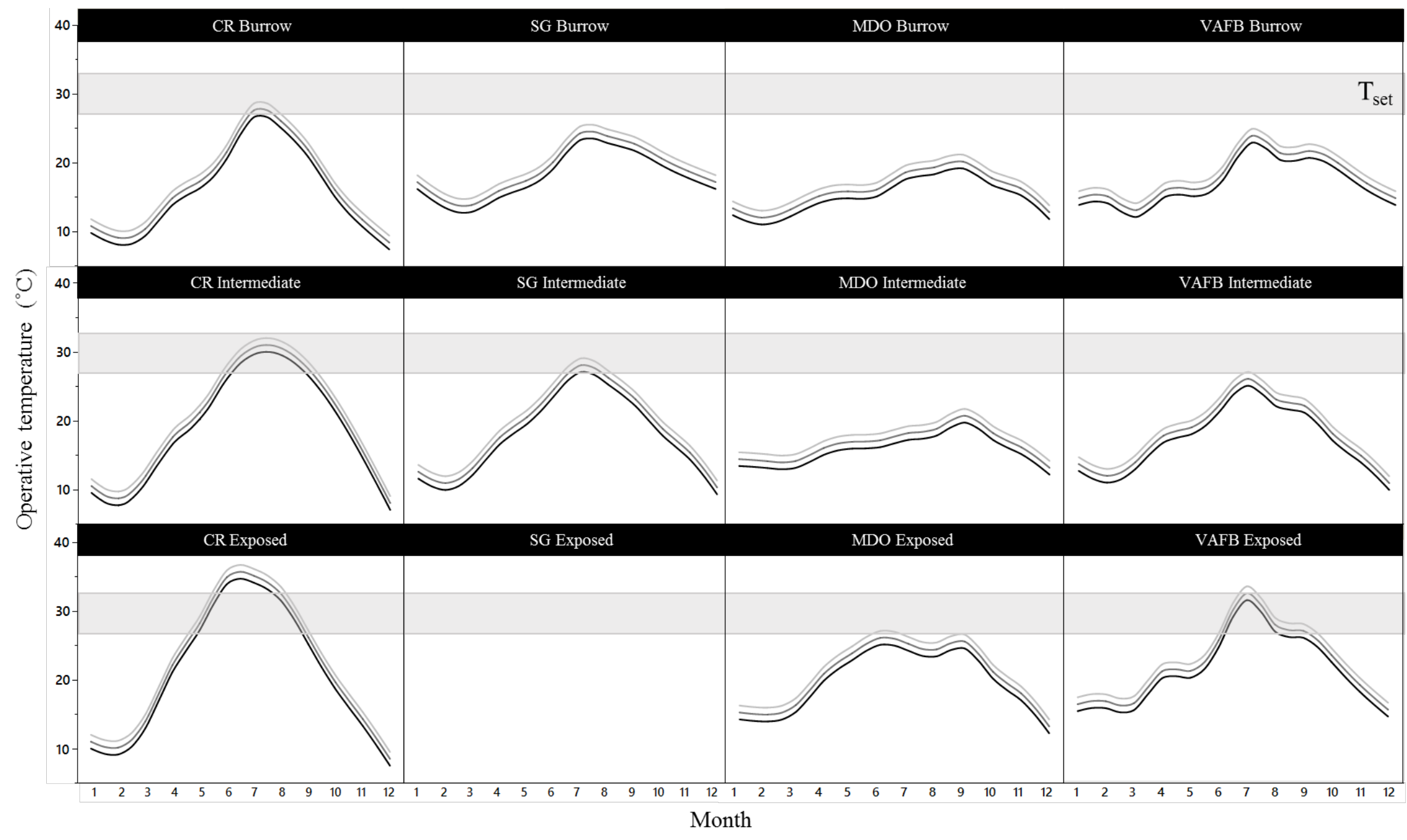

Figure 10. Mean monthly operative temperatures $\left(T_{e}\right)$ for each of the three operative temperature model types (Burrow, Intermediate, Exposed) at current conditions (black line) and with a $1^{\circ} \mathrm{C}$ (dark grey line) and $2^{\circ} \mathrm{C}$ (light grey line) increase in ambient temperature for four sites (CR, SG, MDO, VAFB) on the Central Coast of California. CR and SG represents inland locations and MDO and VAFB represent coastal locations. Grey bars represents the preferred body temperature $\left(\mathrm{T}_{\mathrm{set}}\right)$ of Crotalus oreganus. 
Additionally, thermal quality of each microhabitat type increases (closer to a value of zero) as well as the overall thermal quality of each site with 1 and $2{ }^{\circ} \mathrm{C}$ increases in ambient temperature (Figure 11). With the greatest increase of $2{ }^{\circ} \mathrm{C}, \mathrm{CR}, \mathrm{SG}, \mathrm{MDO}$ and VAFB will respectively experience an overall 10, 12, 13 and $11 \%$ increase in $\mathrm{d}_{\mathrm{e}}$.

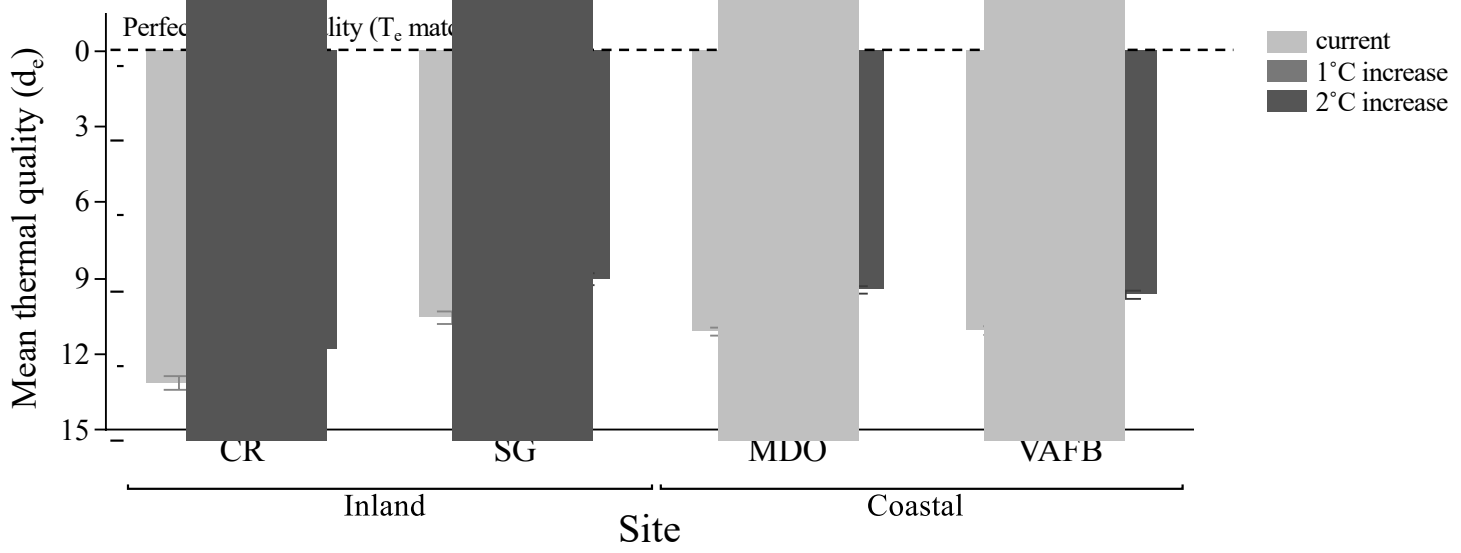

Figure 11. Overall thermal quality $\left(\mathrm{d}_{\mathrm{e}}\right)$ for four study sites $(\mathrm{CR}, \mathrm{SG}, \mathrm{MDO}, \mathrm{VAFB})$ on the Central Coast of California at current conditions and with a $1{ }^{\circ} \mathrm{C}$ and $2{ }^{\circ} \mathrm{C}$ increase in ambient temperatures. Values approaching zero represent higher thermal quality. All sites experience an overall increase in $d_{e}$ as ambient temperatures increase, creating potentially more favorable thermal environments for $C$. oreganus in both coastal and inland locations. Error bars represent \pm 1 SEM.

Maintenance energy requirements (kcal/year) were statistically significantly different when incorporating an annual increase in mean snake $\mathrm{T}_{\mathrm{b}}\left(\mathrm{F}_{5,6}=106.97, \mathrm{p}<\right.$ 0.00001). However, a Tukey post-hoc test revealed no significant differences in energetic requirements with an increase in snake $\mathrm{T}_{\mathrm{b}}$ of $1^{\circ} \mathrm{C}(8.4 \%$ increase in annual maintenance energetic requirements). With a $2{ }^{\circ} \mathrm{C}$ increase from current snake $\mathrm{T}_{\mathrm{b}}$, mean energetic requirements increased by another $17.6 \%$, which was a significant increase from the current and $1{ }^{\circ} \mathrm{C}$ requirements. However, when converted to mean number of squirrels/year, all populations still required roughly 1 or less large meal at any given $T_{b}$ scenario (Table 6). 
Table 6. Mean number of ground squirrels required by an average-sized, adult male Crotalus oreganus from four distinct populations on the Central Coast of California in order to meet baseline annual maintenance energy requirements at current body temperature $\left(\mathrm{T}_{\mathrm{b}}\right)$ conditions and with a $1^{\circ} \mathrm{C}$ and $2^{\circ} \mathrm{C}$ increase in $\mathrm{T}_{\mathrm{b}}$.

\begin{tabular}{lccc}
\hline Site & $\begin{array}{c}\text { Current no. required } \\
\text { squirrels }\end{array}$ & $\begin{array}{c}\text { No. required squirrels with } \\
\mathbf{1}^{\circ} \mathrm{C} \text { increase }\end{array}$ & $\begin{array}{c}\text { No. required squirrels with } \\
\mathbf{2}^{\circ} \mathrm{C} \text { increase }\end{array}$ \\
\hline $\begin{array}{l}\mathrm{CR} \\
\text { (Inland) }\end{array}$ & $0.84 \pm 0.04$ & $0.90 \pm 0.04$ & $1.06 \pm 0.04$ \\
$\mathrm{SG}$ & & & \\
$($ Inland) & $0.77 \pm 0.04$ & $0.86 \pm 0.05$ & $1.01 \pm 0.05$ \\
$\mathrm{MDO}$ & - & & \\
$($ Coastal) & $0.49 \pm 0.04$ & $0.53 \pm 0.05$ & $0.62 \pm 0.04$ \\
$\begin{array}{l}\text { VAFB } \\
\text { (Coastal) }\end{array}$ & $0.52 \pm 0.02$ & & $0.68 \pm 0.02$ \\
\hline
\end{tabular}




\section{Discussion:}

In this study, we demonstrated that coastal and inland populations of $C$. oreganus experience dramatically different climates but utilize behavioral thermoregulation such that the differences in mean active $T_{b}$ are small, and that these differences may not have major impacts on the snakes' energetic needs. Our findings show that $C$. oreganus is a moderately precise thermoregulator (Blouin-Demers \& Weatherhead, 2001) and will therefore likely be able to mitigate the effects inhabiting low-quality thermal habitat by altering frequencies of thermoregulatory behaviors; thus, this species maybe be fairly resilient to changing climates.

\subsection{Preferred Body Temperature $\left(T_{\text {set }}\right)$}

Because there was no significant difference in $\mathrm{T}_{\text {set }}$ among populations, the singular range of $26.3 \pm 1.01^{\circ} \mathrm{C}-32.3 \pm 0.84$ could be used for all thermal quality and accuracy analyses. This large $\mathrm{T}_{\text {set }}$ range aligns with the fact that these snakes are habitat generalists and probably have a wide range of environmental temperature tolerances (Alford \& Lutterschmidt, 2012). Other vipers also exhibit high variation in $\mathrm{T}_{\text {set }}$ within (between $3-6{ }^{\circ} \mathrm{C} \mathrm{IQR}$ ) and among species, ranging from $20.4^{\circ} \mathrm{C}$ to $33.6^{\circ} \mathrm{C}$ (Table 7). This large range of temperature preferences exemplifies the tendency of vipers to exhibit more eurythermic behaviors that are reflective of the environments in which they are found (Brattstrom, 1965; Moore, 1969; Bovo et al., 2012). 
Table 7. Preferred body temperatures $\left(\mathrm{T}_{\mathrm{set}}\right)$ from Crotalus as well as other viper species. Notes indicate any discrepancies or points the authors thought were relevant to their study.

\begin{tabular}{|c|c|c|c|c|}
\hline Species & Reference & $T_{\text {set }}\left({ }^{\circ} \mathrm{C}\right)$ & $n$ & Notes \\
\hline Bothrops insularis & Bovo et al., 2012 & $20.4-26.3$ & 85 & $\begin{array}{l}\text { Interquartile range in winter } \\
\text { and summer }\end{array}$ \\
\hline Crotalus atrox & Brattstrom, 1965 & 27.4 & 8 & - \\
\hline Crotalus cerastes & Moore, 1978 & 25.8 & 37 & $\begin{array}{l}\text { C. mitchellii and C. cerastes } \\
\text { were active at different } \\
\text { times in the study to } \\
\text { minimize competition. } \\
\text { April-December. }\end{array}$ \\
\hline Crotalus horridus & Brown, 1982 & 26.9 & 5 & - \\
\hline Crotalus mitchellii & Moore, 1978 & 31.2 & 31 & April-December \\
\hline Crotalus oreganus & This study & $26.3-32.3$ & 51 & - \\
\hline $\begin{array}{l}\text { Crotalus viridis } \\
\text { oreganus }\end{array}$ & $\begin{array}{l}\text { Brattstrom, } 1965 \\
\text { Moore, } 1969\end{array}$ & $\begin{array}{c}28.9 \\
28-31\end{array}$ & $\begin{array}{c}11 \\
6\end{array}$ & - \\
\hline Crotalus spp. & Brattstrom, 1965 & 29.7 & $\begin{array}{c}\text { atrox }=8 \\
\text { cerastes }=15 \\
\text { enyo }=1 \\
\text { horridus }=5 \\
\text { mitchellii }=3 \\
\text { pricei }=5 \\
\text { ruber }=1 \\
\text { scutulatus }=4 \\
\text { viridis }=11 \\
\text { willardi }=1\end{array}$ & $\begin{array}{l}56 \text { individuals recorded } \\
\text { across } 11 \text { different species }\end{array}$ \\
\hline $\begin{array}{l}\text { Sistrurus } \\
\text { catenatus }\end{array}$ & $\begin{array}{l}\text { Harvey \& } \\
\text { Weatherhead, } 2010\end{array}$ & $30-33.6$ & 34 & - \\
\hline Vipera aspis & Guillon et al., 2014 & 33 & 16 & - \\
\hline Vipera berus & $\begin{array}{l}\text { Herczeg et al., } \\
2007\end{array}$ & $27.8-33.0$ & 26 & $\begin{array}{l}\text { Values taken from males, } \\
\text { females and juveniles }\end{array}$ \\
\hline
\end{tabular}

\subsection{Field Active Body Temperature $\left(T_{b}\right)$}

Our hypothesis that snakes from coastal and inland populations would maintain different field active $\mathrm{T}_{\mathrm{b}} \mathrm{s}$ was supported, in that snakes from coastal sites (MDO, VAFB) had significantly lower $\mathrm{T}_{\mathrm{b}}$ than snakes from inland sites $(\mathrm{CR}, \mathrm{SG})$. It is difficult to 
confirm if differences in ambient temperature are entirely responsible for the differences we see in mean snake $T_{b}$, as variation in $T_{b}$ is also related to body size (Putman \& Clark, 2017), which, in the case of our study, is inextricably linked to source population/site.

All snakes maintained mean field active $\mathrm{T}_{\mathrm{b}} \mathrm{s}$ that were lower than their laboratory $\mathrm{T}_{\text {set, }}$ meaning that the benefits of basking for longer periods of time in order to maintain higher $T_{b}$ appeared to be offset by some form of negative consequence. Specifically, $T_{b}$ values of coastal snakes were lower than that of inland snakes, indicating the possibility of environmental trade-offs impacting the thermoregulatory behavior of these populations. Lengthened basking periods could expose snakes to higher predation risk, most notably from raptors, a predator group that is extremely common on the Central Coast of California and whose diets can include large numbers of snakes (Steenhof \& Kochert, 1985; Selås, 2001; Steenhof \& Kochert, 2006). The coastal snakes we studied appeared to be more active in cooler and foggy conditions than in clear conditions, potentially to avoid exposure to avian predators. Additionally, snakes at the coastal MDO site moved less frequently during warmer weather when marine cloud layers burned off (see below for additional explanations). The low $\mathrm{T}_{\mathrm{b}}$ could also be influenced by selection of ambush sites, where snakes will remain for an extended period of time until a prey item passes within striking distance. These ambush locations frequently occur along small mammal trails in grass or near ground squirrel burrows (Theodoratus \& Chiszar, 2000; Putman et al., 2016) and are often located in shaded microhabitat where opportunities to raise $T_{b}$ are limited, therefore resulting in lowered $T_{b}$ due to the fact that snakes are passively thermoconforming to these environments (Alford \& Lutterschmidt, 2012). 


\subsection{Operative Temperatures $\left(T_{e}\right) /$ Thermal Quality $\left(d_{e}\right)$}

Our hypothesis that coastal sites had overall higher thermal quality than inland sites was supported (if we assume that SG would have a similar thermal quality to CR had we been able to include values from exposed OTMs), although there was no significant difference in annual overall mean operative temperatures $\left(T_{e}\right)$. The lack of overall difference in mean $T_{e}$ is likely due to the greater variance of temperatures in inland sites throughout the year relative to coastal sites, creating similar means. However, the variation of available temperatures among and within these sites is best demonstrated by the significant variation in thermal quality of each microhabitat. At both inland sites and at VAFB, burrow habitats consistently had the best thermal quality. However, at MDO, burrows were the least favorable of the three microhabitats, maintaining temperatures that were often much lower than the $\mathrm{T}_{\text {set }}$ of $C$. oreganus. As previously mentioned, this is one possible explanation for the repeated observations of snakes at MDO moving more frequently above ground than at the other sites, even at lower ambient temperatures.

While OTMs allow us to produce a coarse estimate of the thermal landscape available to animals, we are unable to account for the entire thermal configuration of the landscape (Sinclair et al., 2016). The distribution of thermal resources could greatly impact observed behaviors, field-active $T_{b}$, and energy expenditure of each of these four populations. A more detailed analysis of thermal landscape configuration (i.e. examining more microhabitat types and distance between thermal resources) within each of these sites would help elucidate some of the drivers of differences in field active $T_{b}$ observed in 
these populations of $C$. oreganus and in turn provide a more complete pictures of the influence of habitat on snake physiology and ecology.

\subsection{Thermoregulatory Accuracy $\left(d_{b}\right)$}

We were surprised to find that snakes in more thermally constrained environments (inland sites) thermoregulated more accurately than snakes at more stable climates (coastal populations). While this phenomenon has been documented in multiple small lizard species (Gunderson \& Leal, 2012; Sagonas et al., 2013), the number of studies reporting this in large-bodied reptiles is limited, particularly in snakes (Row \& Blouin-Demers, 2006; Besson \& Cree, 2010). It is possible that the higher thermal quality of coastal sites may result in longer periods of time where ambient temperatures are closer to $C$. oreganus $\mathrm{T}_{\text {set, }}$, putting less pressure on snakes to actively thermoregulate. Meanwhile, snakes at inland sites may be experiencing more extreme changes in temperature approaching physiologically stressful values that prompt snakes to seek thermally favorable microhabitats more often. Additionally, Besson \& Cree (2010) found that tuataras in thermally-constrained environments thermoregulated more accurately when conditioned to expected shorter daily periods of thermally-favorable activity hours in order to maximize available activity time. It is possible that snakes at inland sites are behaving similarly to increase physiological performance for other activities (e.g. mate searching, ambush, etc.) during the more limited times of day where temperatures are within or near $\mathrm{T}_{\text {set. }}$. 


\subsection{Thermoregulatory Effectiveness (E)}

Although our sample size for $E$ calculations was greatly reduced, the data we gathered are consistent with our other findings relating to thermal ecology, even though it did not support our original hypothesis that snakes from the inland sites would be less effective at thermoregulating than the coastal populations. When comparing our $E$ values to previous experiments on other large-bodied snakes, our study animals demonstrated similar patterns of thermoregulatory behavior in that snakes in habitats of lower thermal quality actually thermoregulated more effectively than snakes in higher quality habitat (Blouin-Demers \& Weatherhead, 2001; Row \& Blouin-Demers, 2006; Bovo et al., 2012). The most likely explanation for this is similar to our discussion on $d_{b}$ in that snakes in less thermally favorable environments feel more detectable pressure to seek microhabitats within their $\mathrm{T}_{\text {set }}$ (see above section).

\subsection{Behavior}

Because air temperature is an important predictor for thermoregulatory behaviors in reptiles (Huey, 1982), we hypothesized that coastal rattlesnakes would behave differently than inland rattlesnakes to maintain their preferred $\mathrm{T}_{\mathrm{b}}$. Our results support this hypothesis, showing that thermoregulatory behavior is used to cope with differing environmental conditions. Likely due to the higher daytime air temperatures, rattlesnakes at the inland $\mathrm{CR}$ site remained underground for longer periods, which is consistent with our findings that the exposed OTMs at CR had the poorest thermal quality of any microhabitat. 
Although both ambush and transit behaviors could reliably be predicted by air temperature, it was not a useful environmental predictor for the other three behaviors we observed (hiding, basking, and resting). However, it should be noted that air temperature is just one of the many factors that play a significant role in ectotherm behavior (Moore, 1969); other variables such as predator avoidance, competition, and other climatic variables (wind speed, relative humidity, cloud cover) have heavy influences on the behaviors observed in these snakes. For example, high wind speeds may impact a reptile's basking behavior by increasing convective and evaporative heat loss (Foley \& Spotila, 1978). Cloud coverage and relative humidity also play significant roles in insolation (Twomey et al., 1984) and evaporation (Girard et al., 2008). Substrate temperature plays a role for snakes that demonstrate thigmothermic regulation (Moore, 1969; Bovo et al. 2012). Additionally, the site-to-site variation in these biotic and abiotic factors could account for the fact that site alone was also a significant predictor for the behaviors of basking and hiding. For three of the sites (CR, SG, VAFB), hotter air temperatures increased the probability that a snake would be in transit, which agrees with another recent study of a $C$. oreganus population in an inland oak savanna habitat (Putman \& Clark, 2017). In contrast, the coastal MDO field site showed the opposite trend from the three other field sites: as air temperatures increased, transit behavior decreased. One possible explanation for this difference is that MDO is a popular state park and the only field site with consistent public access. Higher temperatures may be more appealing for human visitors and cause increased foot traffic. The higher perceived "predator" activity, along with the thermoregulatory drivers mentioned earlier, may contribute to the reduced transit behavior as temperature increases at MDO.

Our predictive model showed that ambush behavior increased as ambient air temperature increased in coastal field sites but decreased with increased temperature in 
inland field sites. Putman and Clark (2017) also investigated the relationship between the ambush behavior and ambient air temperature in C. oreganus. Their field site (Blue Oak Ranch Reserve, Santa Clara County, CA) has similar air temperatures to our inland sites (Western Regional Climate Center, 2019), and their results agree with our Ambush probability model for inland sites ( $\mathrm{SG}$, and $\mathrm{CR}$ ) in that, as air temperatures increase, the probability of observing a snake in ambush decreased. Comparatively, our study addresses the ambush behavior in coastal field sites. Rattlesnakes in coastal field sites are more likely to be in ambush as ambient temperature increases, opposing the trend in inland sites. This may result from the frequency of the ambush behavior coinciding with frequencies of local prey activities (Bovo et al. 2012). Prey may also be confined to similar thermal limitations as rattlesnakes, and at hotter inland sites prey may be less active at midday to prevent overheating (Vinne et al., 2015), thus explaining the differences in behavior between coastal and inland sites.

\subsection{Energetics}

While overall RMR differed between coastal and inland populations, there was no significant difference among mass-adjusted RMRs of the two population types, even with the distinctly different climates experienced by these populations. This suggests that ambient air temperature may not play a significant role in differences in rattlesnake RMR and that the driving factor for differences in overall metabolic rates, and therefore energetic needs, is the actual mass of the animal (Dorcas et al., 2004).

Upon closer examination of the data, we found that adult, male snakes collected from inland sites were significantly larger on average than snakes from coastal sites. 
There are several possible explanations for this phenomenon that may or may not be related to the thermal landscape available to these populations, but we find three to be most plausible. First, trends in ectotherm size related to Bergmann's rule may not be only restricted to latitudinal differences in climate, but also to general ecosystem types. Bergmann's rule states that endothermic animals tend to increase in body size as one moves further away from the tropics (Bergmann, 1847); however, the opposite of this trend is seen regarding ectotherms, as the generally warmer and more stable climates of the tropics promote a longer active season and more favorable thermal environments for ectotherms, therefore promoting a general increased body size of species closer to the equator (Mousseau, 1997). The warmer active season $T_{e}$ of the inland sites could have similar effects on the body size and growth rates of the snakes living in these areas, while the relatively constant availability of water at these sites (historically via natural wetlands and currently via ponds or cattle troughs) could offset the negative effects of living in semi-arid habitats (Amarello et al., 2010). Second, coastal sites could be more constrained by higher levels of competition for resources such as food, space, and mates due to higher population densities. It has been suggested by Beaupre (1995) that snakes that are more limited energetically, either because of lower prey densities or increased competition, have lower growth rates and therefore smaller age specific size. Third, differences in coastal and inland snakes could be a result of population demographics, either in the form of inland sites having overall older populations (rattlesnakes experience indeterminate growth and thus older snakes are often larger; Frosman, 1993), or inland snakes could be genetically predisposed to grow larger. However, it is most likely that the 
differences we see in size are plastic responses to variation in habitat-specific availability of resources (Madsen \& Shine, 1993).

Regardless of the mechanism responsible for the size differences in the populations, the resulting differences in RMRs means that snakes at inland sites require on average $1.6 \mathrm{x}$ as much food as coastal snakes, simply for maintenance metabolism. It is important to note that these metabolic calculations are only theoretical and do not encompass energetically costly activities such as digestion and/or movement through the environment for mate-seeking, predator avoidance, and ambush site selection (Beaupre, 1996). A logical next step to obtain data on the field-active metabolic rates of these animals would be to use doubly-labeled water for an extended time period to quantify isotope turnover rates and therefore carbon dioxide production (Beaupre, 2008).

\subsection{Climate Change Projections}

While climate change is generally predicted to have an overall negative effect on ectotherms (Sinervo et al., 2010), it is possible that small increases in ambient temperature may prove beneficial to rattlesnakes in central California, in that the overall thermal quality of all microhabitats at all field sites is projected to increase. A larger proportion of daily $\mathrm{T}_{\mathrm{e}}$ will fall within the $\mathrm{T}_{\text {set }}$ range of this species, therefore increasing available activity time. This may translate into additional opportunities to find resources such as mates and food, as well as longer active seasons. In contrast, the availability of this increase in active hours and favorable temperatures may have additional energetic consequences in that the metabolic rates of these snakes may rise with increasing temperatures, therefore requiring the animal to obtain additional energetic resources. 
However, as our calculations and other studies have shown (Beaupre, 1995; Beck, 1995; Beaupre \& Duvall, 1998b), the metabolic needs of these snakes are incredibly low, with current baseline maintenance energetic demands being met with less than a single large meal per year. Even with small increases in mean active $\mathrm{T}_{\mathrm{b}}$ resulting from a $1{ }^{\circ} \mathrm{C}$ or $2{ }^{\circ} \mathrm{C}$ increase in ambient temperature, annual caloric requirements can still be met with a single large prey item and therefore, it is possible that increases in baseline energetic needs may be minimally consequential. Furthermore, evidence from this study suggests that $C$. oreganus is a consistent thermoregulator and overall small changes in ambient temperature will likely not dramatically shift the $T_{b}$ these snakes experience. It is true that these theoretical calculations are limited to the scope of energetic needs of snakes from which they were calculated (i.e., fasted snakes unable to thermoregulate in a metabolic chamber at a resting state), so these results must also be considered in an ecological context. This means we need to take into account possible alterations in snake behavior as a response to changing temperatures, which therefore may increase energetic needs beyond the scope of these models. 


\section{Conclusions:}

Overall, rattlesnakes are ideal model organisms for examining the physiological effects of climate on large-bodied reptiles. Their life history traits, simple behaviors, and metabolism are well-studied, providing a strong foundation for examining the effects of difference environments and climates on basic physiological functions. Additionally, large-scale comparative studies among multiple populations of a given species can greatly enhance our understanding of the effects of anthropogenic climate change on biodiversity. While small increases in ambient temperature may prove beneficial to rattlesnakes on the Central Coast of California, larger alterations in climates may affect rattlesnake environments in negative ways and have cascading effects within their biotic communities. However, our study suggests that snakes may be more robust to these changes than other ectotherms for several reasons: even though snakes found in milder, coastal habitats maintain slightly lower field active $T_{b}$ than snakes from warmer, inland habitats, these differences may not be as biologically significant as other physiological differences between the populations, most notably body size. Additionally, a wideranging $\mathrm{T}_{\text {set}}$, plasticity in thermoregulatory behavior, and overall low metabolic demands may help mitigate changes in environmental temperatures these animals will experience, even across extremely variable habitat types. 


\section{References:}

Aldridge, R. D. (2002). The link between mating season and male reproductive anatomy in the rattlesnakes Crotalus viridis oreganus and Crotalus viridis helleri. Journal of Herpetology. 36(2): 295-300.

Alford, J.G., \& Lutterschmidt, W. I. (2012). Modeling energetic and theoretical costs of thermoregulatory strategy. Journal of Biological Dynamics. 6(1): 63-79

Amarello, M., Nowak, E.M., Taylor, E.N., Schuett, G.W., Repp, R.A., Rosen, P.C., \& Hardy, D.L Sr. (2010). Potential environmental influences on variation in body size and sexual size dimorphism among Arizona populations of the western diamond-backed rattlesnake (Crotalus atrox). Journal of Arid Environments. 74: $1443-1449$.

Araújo, M. B., Thuiller, W., \& Pearson, R. G. (2006). Climate warming and the decline of amphibians and reptiles in Europe. Journal of Biogeography. 33(10): 17121728.

Ashton, K. G. (2001). Body size variation among mainland populations of the Western Rattlesnake (Crotalus viridis). Evolution. 55(12): 2523-2533.

Ashton, K. G. \& de Queiroz, A. (2001). Molecular systematics of the western rattlesnake, Crotalus viridis (Viperidae), with the comments on the utility of the DLoop in phylogenetic studies of snakes. Molecular Phylogenetic Evolution. 21: $76-189$.

Aubret, F., \& Shine, R. (2010). Thermal plasticity in young snakes: how will climate change affect the thermoregulatory tactics of ectotherms? Journal of Experimental Biology. 213(2): 242-248. 
Bakken, G.S. (1992). Measurement and application of operative and standard operative temperatures in ecology. American Zoologist. 32: 194-216.

Bakken, G. S., \& Gates, D. M. (1975). Heat-transfer analysis of animals: some implications for field ecology, physiology, and evolution. Perspectives of Biophysical Ecology. 255-290

Beaupre, SJ. (1995). Effects of geographically variable thermal environment on bioenergetics of Mottled Rock Rattlesnakes. Ecology. 76(5): 1655-1665. . (1996). Field metabolic rate, water flux, and energy budgets of Mottled Rock Rattlesnakes, Crotalus lepidus, from two populations. Copeia. 2: 319-329. . (2002). Modeling Time-Energy allocation in Vipers: Individual responses to environmental variation and implications for populations. Biology of the Vipers, Eagle Mountain Publishing, Eagle Mountain, Utah. 463-481. . (2008). Annual variation in time-energy allocation by Timber Rattlesnakes (Crotalus horridus) in relation to food acquisition. The Biology of Rattlesnakes, Loma Linda University Press, Loma Linda, California. 1-11.

Beaupre, S.J., \& Duvall, D. (1998)a. Integrative biology of rattlesnakes. BioScience. 48(7): 531-538. . (1998)b. Variation in oxygen consumption of the western diamondback rattlesnake (Crotalus atrox): implications for sexual size dimorphism. Journal of Comparative Physiology B. 168: 497-506.

Beck, D.D. (1995). Ecology and energetics of three sympatric rattlesnake species in the Sonoran Desert. Journal of Herpetology. 29(2): 211-223. 
Bergmann, C. (1847). On the relations of the heat economy of animals to their size. Gottinger Studien. 1847(3): 595-708.

Besson, A.A., \& Cree, A. (2010). A cold-adapted reptiles becomes a more effective thermoregulator in a thermally challenging environment. Oecologia. 163: 571-581.

Bickford, D., Howard, S.D., Ng, D.J.J., \& Sheridan, J.A. (2010). Impacts of climate change on the amphibians and reptiles of Southeast Asia. Biodiversity Conservation. 19(4): 1043-1062

Birchard, G. F., Nelson, N. J., Daugherty, C. H. (2006). A circadian rhythm in oxygen consumption rate in juvenile tuatara (Sphenodon punctatus). New Zealand Journal of Zoology. 33(3): 185-188.

Blouin-Demers, G., \& P.J. Weatherhead. (2001). Thermal ecology of black rat snakes (Elaphe obsoleta) in a thermally challenging environment. Ecology. 82(11): 30253043.

Blouin-Demers, G., \& Weatherhead, P. (2002). Habitat-Specific behavioral thermoregulation by black rat snakes (Elaphe obsoleta obsoleta). Oikos. 97(1): 5968.

Bogert, C. M. (1949). Thermoregulation in reptiles, a factor in evolution. Evolution: International Journal of Organic Evolution. 3(3): 195-211.

Böhm, M., Collen, B., Baillie, J.E.M., Bowles, P., Chanson, J., Cox, N., Hammerson, G., Hoffman, M., Livingston, S. R., Ram, M., et al. (2013). The conservation status of the world's reptiles. Biological Conservation. 157: 372-385. 
Bovo, R. P., Marques, O.A.V., \& Andrade, D.V. (2012). When basking is not an option: thermoregulation of a Viperid snake endemic to a small island in the South Atlantic of Brazil. Copeia. 2012: 408-418.

Brattstrom, B.H. (1965). Body temperatures of reptiles. American Midland Naturalist. 73: $376-422$.

Brown, W.S., Pyle, D.W., Greene, K.R., \& Friedlaender, J.B. (1982). Movements and temperature relationships of Timber Rattlesnakes (Crotalus horridus) in Northeastern New York. Journal of Herpetology. 16: 151-161.

Brown, G.P., \& Weatherhead, P.J. (2000). Thermal ecology and sexual size dimorphism in Northern water snakes, Nerodia sipedon. Ecological Monographs. 70: $311-330$.

Brusch, G.A. IV, Taylor, E.N, \& Whitfield, S.M. (2016). Turn up the heat: thermal tolerances of lizards at La Selva, Costa Rica. Oecologia. 180: 325-334.

California Energy Commission (2019). Cal-Adapt: Exploring California's climate change research. State of California. http://cal-adapt.org/

Capehart, G.D., Escallón, C., Vernasco, B.J., Moore, I.T. \& Taylor, E.N. (2016). No drought about it: effects of supplemental hydration on the ecology, behavior, and physiology of free-ranging rattlesnakes. Journal of Arid Environments. 134: 79-86.

Charland, M.B., Gregory, P.T. \& Columbia, B. (1990). The Influence of female reproductive status on thermoregulation in a viviparous snake, Crotalus viridis. Copeia. 4: 1089-1098.

Chimineas Ranch Foundation. (2019). Mission: Who we are \& what we do. http://www.chimineasranchfoundation.org/mission.html 
Claunch, N.M., Frazier, J.A., Escallón, C., Vernasco, B.J., Moore, I.T., \& Taylor, E.N. (2017). Physiological and behavioral effects of exogenous corticosterone in a freeranging ectotherm. General and Comparative Endocrinology. 248: 87-96.

Clusella-Trullas, S., Blackburn, T.M. \& Chown, S.L. (2011). Climatic predictors of temperature performance curve parameters in ectotherms imply complex responses to climate change. The American Naturalist. 177(6): 738-751.

Dawson, W. (1975). On the physiological significance of preferred body temperatures of reptiles. Perspectives of Biophysical Ecology. 443-473.

Dorcas, M.E., Hopkins, W.A., \& Roe, J.H. (2004). Effects of body mass and temperature on standard metabolic rate in the Eastern diamondback rattlesnake (Crotalus adamanteus). Copeia. 1: 145-151.

Dzialowski, E.M. (2005). Use of operative temperature and standard operative temperature models in thermal biology. Journal of Thermal Biology. 30: 317-334.

Evans, F. C. \& Holdenried, R. (1943) A population study of Beechy ground squirrel in Central California. Journal of Mammalogy. 24(2): 231-260.

Fitch, H.S. (1949). Study of snake populations in central California. American Midland Naturalist. 41: 513-579.

Fitzgerald, M., Shine., \& Lemckert F. (2003). A reluctant heliotherm: thermal ecology of the arboreal snake Hoplocephalus stephensii (Elapidae) in dense forest. Journal of Thermal Biology. 28: 515-524.

Foley, R., \& Spotila, J. (1978). Effect of wind speed, air temperature, body Size and vapor density difference on evaporative water loss from the turtle Chrysemys scripta. Copeia. 4: 627-634. 
François, R., Henry, L., \& Müller, K. (2018) dplyr: A grammar of data manipulation. R package version 0.7 .7 .

Frosman, A. (1993). Survival in relation to body size and growth rate in the adder, Vipera berus. Journal of Animal Ecology. 62: 647-655.

Gibbons J.W., Scott, D.E., Ryan, T.J, Buhlmann, K.A, Tuberville, T.D., Metts, B.S., Greene, J.L, Mills, T., Leiden, Y., Poppy, S., \& Winne, C.T. (2000). The global decline of reptiles, déjà vu amphibians. BioScience. 50: 653-666.

Girard, F., Antoni, M., Faure, S., \& Steinchen, A. (2008). Influence of heating temperature and relative humidity in the evaporation of pinned droplets, colloids and surfaces A: Physicochemical and Engineering Aspects. 323(1-3): 36-49.

Grigaltchik, V.S, Ward, A.J.W. \& Seebacher, F. (2012). Thermal acclimation of interactions: differential responses to temperature change alter predator-prey relationship. Proceeding of the Royal Society B. 279: 4058-4064.

Guillon, M., Guiller, G., DeNardo, D.F., \& Lourdais, O. (2014). Microclimate preferences correlate with contrasted evaporative water loss in parapatric vipers at their contact zone. Canadian Journal of Zoology. 92: 81-86.

Gunderson, A., \& Leal, M. (2012). Geographic variation in vulnerability to climate warming in a tropical Caribbean lizard. Functional Ecology. 26(4): 783-793.

Harvey, D. S. \& Weatherhead, P. J. (2010). Habitat selection as the mechanism for thermoregulation in a northern population of massasauga rattlesnakes (Sistrurus catenatus). Ecoscience 17: 411-419. 
Herczeg, G., Gonda, A., Perala, J., Saarikivi, J., Tuomola, A., \& Merila, J. (2007).

Ontogenetic differences in the preferred body temperature of the European adder Vipera berus. Herpetological Journal. 17: 58-61.

Hertz, P. E., Huey, R. B., \& Stevenson, R. D. (1993). Evaluating temperature regulation by field-active ectotherms: the fallacy of the inappropriate question. American Naturalist. 142: 796-818.

Holding, M. L., Margres, M. J., Rokyta, D. R, \& Gibbs, H. L. (2018) Local prey community composition and genetic distance predict venom divergence among populations of the northern Pacific rattlesnakes. Journal of Evolutionary Biology. 31: $1531-1528$.

Huey, R. B. (1982). Temperature, physiology, and the ecology of Reptiles. Biology of the Reptilia, Academic Press, London, United Kingdom. 25-91.

Ihlow, F., Dambach, J., Engler, J.O., Flecks, M., Hartmann, T., Nekum, S., Rajaei, H., \& Rodder, D. (2011) On the brink of extinction? How climate change may affect global chelonian species richness and distribution. Global Change Biology. 18(5): $1520-1530$.

Kearney, M., Shine, R., \& Porter, W. P. (2009). The potential for behavioral thermoregulation to buffer "cold-blooded" animals against climate warming. Proceedings of the National Academy of Sciences. 106(10): 3835-3840.

Klauber, L.M. (1972). Rattlesnakes: Their Habits, Life History, and Influences on Mankind. Vol. 1, University of California Press, Berkeley, California.

Kaufman, D. W., Kaufman, G. A., \& Wiener, J. G. (1975) Energy equivalents for sixteen species of xeric rodents. Journal of Mammalogy. 56: 946-949. 
Lelièvre, H., Blouin-Demers, G., Pinaud, D., Lisse, H., Bonnet, X., \& Lourdais, O. (2011) Contrasted thermal preferences translates into divergences in habitat use and realized performance in two sympatric snakes. Journal of Zoology. 284: $265-$ 275.

Lind, C., Husak, J. F., Eikenaar, C., Moore, I. T., \& Taylor, E. N. (2010). The relationship between plasma steroid hormone concentrations and the reproductive cycle in the Northern Pacific rattlesnake, Crotalus oreganus. General and Comparative Endocrinology. 166: 590-599.

Lutterschmidt, W. I. and Reinert, H. K. 2012. Modeling body temperature and thermal inertia of large-bodied reptiles : Support for water-filled biophysical models in radiotelemetric studies. Journal of Thermal Biology, 37(4): 282-285.

Mackessy, S., Williams, K., \& Ashton, K. (2003). Ontogenetic variation in venom composition and diet of Crotalus oreganus concolor: a case of venom paedomorphosis? Copeia. 4: 769-782.

Madsen, T. \& Shine, R. (1993). Phenotypic plasticity in body sizes and sexual size dimorphism in European grass snakes. Evolution. 47(10): 321-325.

Millar, R. B. \& Anderson, M. J. (2004). Remedies for pseudoreplication. Fisheries Research. 70: 397-407.

Moore, R.G. (1969). Thermoregulation in the Western rattlesnakes, Crotalus viridis. Master's Thesis, Department of Biological Science, California State College at Hayward. 
. (1978). Seasonal and daily activity patterns and thermoregulation in the

Southwestern Speckled rattlesnake (Crotalus mitchellii pyrrhus) and the Colorado

Desert sidewinder (Crotalus cerastes laterorepens). Copeia. 4: 439-442.

Mousseau, T. A. (1997). Ectotherms follow the converse to Bergmann's rule.

Evolution. 51: 630-632

Pelegrin, N., \& Bucher, E.H. (2012). Effects of habitat degradation on lizard assemblage in arid Chaco, central Argentina. Journal of Arid Environments. 79: 13-19.

Pook, C., Wüster W., \& Thorpe R. (2000). Historical biogeography of the Western Rattlesnake (Serpentes: Viperidae: Crotalus viridis), inferred from mitochondrial DNA sequence information. Molecular Phylogenetics and Evolution. 15: 269-282.

Putman, B. J., Lind, C., \& Taylor, E. N. (2013). Does size matter? Factors influencing the spatial ecology of Northern Pacific rattlesnakes (Crotalus oreganus oreganus) in Central California. Copeia. 3: 485-492.

Putman, B. J., Barbour, M. A., \& Clark, R. W. (2016). The foraging behavior of freeranging rattlesnakes (Crotalus oreganus) in California ground squirrel (Otospermophilus beecheyi) colonies. Herpetologica. 72(1): 55-63.

Putman, B.J., \& Clark, R.W. (2017). Behavioral thermal tolerances of free-ranging rattlesnakes (Crotalus oreganus) during the summer foraging season. Journal of Thermal Biology. 65(2017): 8-15.

R Development Core Team. (2015). R: A language and environment for statistical computing. Vienna: R Foundation for Statistical Computing. 
Row, J.R. \& Blouin-Demers, G. (2006). Thermal quality influence effectiveness of thermoregulation, habitat use, and behavior in milk snakes. Oecologica. 148: 1-11.

Rowe, M.P. \& Owings, D.H. (1990). Probing, assessment, and management during interactions between ground squirrels and rattlesnakes. Ethology. 86: 237-249.

Secor, S.M., \& Nagy, K.A. (1994). Bioenergetic correlates of foraging mode for the snakes Crotalus cerastes and Masticophis flagellum. Ecology. 5: 1600-1614.

Selås, V. (2001). Predation on reptiles and birds by the common buzzard, Buteo, in relation to changes in its main prey, voles. Journal of Canadian Zoology. 79(11): 2086-2093.

Sinclair, B.J., Marshall, K.E., Sewell, M.A., Levesque, D.L., Willett, C.S., Slotsbo, S., Dong, Y., Harley, C.D.G., Marshall, D.J., Helmuth, B.S. et al. (2016). Can we predict ectotherm responses to climate change using thermal performance curves and body temperatures? Ecology Letters. 19: 1372-1385.

Sinervo, B., Méndez-de-la-Cruz, F., Miles, D.B., Heulin, B., Bastiaans, E., VillagránSanta Cruz, M., Lara-Resendiz, R., Martínez-Méndez, N., Calderón-Espinosa, M.L, Meza-Lázaro, R.N., et al. (2010). Erosion of lizard diversity by climate change and altered thermal niches. Science. 328: 894-899.

Sparks, A.M., Lind, C., \& Taylor, E. N. (2015). Diet of the Northern Pacific Rattlesnake (Crotalus o. oreganus) in California. Herpetological Review. 46(2): 161-165.

Steenhof, K. \& Kochert, M. N. (1985). Dietary shifts of sympatric buteos during a prey decline. Oecologia. 66: 6-16. 
(2006). Dietary responses of three raptor species to changing prey

densities in a natural environment. The Journal of Animal Ecology. 57(1): 37.

Sunagar, K. , Undheim, E.A.B., Scheib, H., Gren, E.C.K., Cochran, C., Person, C.E.,

Koludarov, I., Kelln, W., Hayes, W.K., King, G.F., Antunes, A., \& Fry, B.G.

(2014). Intraspecific venom variation in the medically significant Southern Pacific

rattlesnake (Crotalus oreganus helleri): Biodiscovery, clinical and evolutionary

implications. Journal of Proteomics. 99: 68-83.

Taylor, E.N., DeNardo, D.F., \& Jennings, D.H. (2004). Seasonal steroid hormone

levels and their relation to reproduction in the Western Diamond-backed

rattlesnake, Crotalus atrox (Serpentes:Viperidae). General and Comparative

Endocrinology. 136: 328-337.

Taylor, E.N. \& DeNardo, D.F. (2005). Reproductive ecology of Western Diamondbacked rattlesnakes (Crotalus atrox) in the Sonoran Desert. Copeia. 1: 152-158.

Theodoratus, D.H., \& Chiszar, D. (2000). Habitat selection and prey odor in the foraging behavior of Western rattlesnakes (Crotalus viridis). Behaviour. 137(1): 119-135.

TWC Product and Technology LLC. (2019) The Weather Channel: Carrizo Plain National Monument Monthly Weather, IBM Cloud. https://weather.com/weather/monthly/l/CABLCARII:13:US

Twomey, S.A., Piepgrass, M., \& Wolfe, T.L. (1984). An assessment of the impact of pollution on global cloud albedo. Tellus B: Chemical and Physical Meteorology. 36(5): 356-366. 
Underwood, E., Ustin, S., \& DiPietro, D. (2003). Mapping nonnative plants using hyperspectral imagery. Remote Sensing of Environment. 86(2): 150-161.

University of California Reserve System: Natural Resources. (2019). January. UC Reserve Santa Barbara. http://sedgwick.nrs.ucsb.edu/weather/daily-weather-2007

Urban, M.C. (2015). Accelerating extinction risk from climate change. Science. 348(6234): 571-573.

Vinne, V., Gorter, J., Riede, S., \& Hut, R. (2015). Diurnality as an energy-saving strategy: energetic consequences of temporal niche switching in small mammals. Journal of Experimental Biology. 218: 2585-2593.

Waldshmidt, S.R, Jones, S.M., \& Porter, W.P. (1986). The Effect of Body Temperature and Feeding Regime on Activity, Passage Time, and Digestive Coefficient in the lizard Uta stansburiana. Physiological Zoology. 59(3): 376-383.

Walther, G., Post, E., Convey, P., Menzel, A., Parmesan, C., Beebee, T. J., Fromentin, J., Hoegh-Guldberg, O., \& Bairlein, F. (2002). Ecological responses to recent climate change. Nature. 416: 389-395.

Weatherforyou. (2019). Daily normals for Montana De Oro State Park, CA. Weatherforyou. https://www.weatherforyou.com/reports/index.php?forecast=norms\&zipcode $=\&$ pa nds $=\&$ place $=$ montana + de + oro + state + park $\&$ state $=$ ca $\&$ country $=$ us $\&$ day $=$ all $\% 2 \mathrm{Cm}$ onth\&month $=12$ 
Weather Spark. (2018) Average weather at Lompoc, Vandenberg Air Force Base, California, USA. Cedar Lake Ventures, Inc.

https://weatherspark.com/y/145288/Average-Weather-at-Lompoc-VandenbergAir-Force-Base;-California;-United-States-Year-Round

Western Regional Climate Center. (2017). Cooperative Climatological Data

Summaries: S. California. Western Regional Climate Center (WRCC) and the National Ocean and Atmospheric Administration.

https://wrcc.dri.edu/summary/Climsmsca.html

Whitfield, S.M., Bell, K.E., Philippi, T., Sasa, M., Bolaños, F., Chavez, G., Savage, J.M., \& Donnelly, M.A. (2007). Amphibian and reptile declines over 35 years at La Selva, Costa Rica. Proceedings of the National Academy of Sciences. 104(20): $8352-8$ 


\section{Appendices:}

\section{A. Supplementary Tables}

Table S1. Environmental descriptions of four study sites on the Central Coast of California. Most notable for this study are the similarities in ambient temperatures and dominant vegetation within Inland and Coastal sites.

\begin{tabular}{|l|c|c|c|l|l|l|l|}
\hline Site & $\begin{array}{l}\text { Average } \\
\text { Annual } \\
\text { Temp. } \text { ( }^{\circ} \text { C) }\end{array}$ & $\begin{array}{l}\text { Average } \\
\text { Annual } \\
\text { Rainfall } \\
(\boldsymbol{c m})\end{array}$ & $\begin{array}{l}\text { Elevation } \\
(\boldsymbol{m})\end{array}$ & Lat/Long & $\begin{array}{l}\text { Dominant } \\
\text { Vegetation }\end{array}$ & Human Use & Sources \\
\hline $\begin{array}{l}\text { CR } \\
\text { (Inland) }\end{array}$ & $-9.4-46.7$ & $18-23$ & 671 & $\begin{array}{l}35.1658^{\circ} \mathrm{N} \\
119.8696^{\circ} \mathrm{W}\end{array}$ & $\begin{array}{l}\text { Chaparral, Oak } \\
\text { Savanna, and } \\
\text { Grassland Plains }\end{array}$ & Cattle grazing & $\begin{array}{l}\text { Chimineas Ranch } \\
\text { Foundation, 2019; } \\
\text { TWC Product and } \\
\text { Technology, 2019 }\end{array}$ \\
\hline $\begin{array}{l}\text { SG } \\
\text { (Inland) }\end{array}$ & $-5-37.7$ & $\sim 38$ & $290-793$ & $\begin{array}{l}34.6928^{\circ} \mathrm{N} \\
120.0406^{\circ} \mathrm{W}\end{array}$ & $\begin{array}{l}\text { Chaparral, Oak } \\
\text { Savanna, and } \\
\text { Grassland Plains }\end{array}$ & $\begin{array}{l}\text { Private reserve } \\
\text { partially used for cattle } \\
\text { grazing }\end{array}$ & $\begin{array}{l}\text { University of } \\
\text { California Natural } \\
\text { Reserve System: } \\
\text { Sedgwick Reserve, } \\
2019\end{array}$ \\
\hline $\begin{array}{l}\text { MDO } \\
\text { (Coastal) }\end{array}$ & $5-20.6$ & $0-9.4$ & $0-411$ & $\begin{array}{l}35.2639^{\circ} \mathrm{N} \\
120.8632^{\circ} \mathrm{W}\end{array}$ & $\begin{array}{l}\text { Coastal Scrub, } \\
\text { Chaparral }\end{array}$ & $\begin{array}{l}\text { Frequent trail use by } \\
\text { hikers }\end{array}$ & $\begin{array}{l}\text { Capehart et al., 2016; } \\
\text { Weatherforyou.com, } \\
2019\end{array}$ \\
\hline $\begin{array}{l}\text { VAFB } \\
\text { (Coastal) }\end{array}$ & $5.5-21.7$ & $0-8.1$ & $156-700$ & $\begin{array}{l}34.7420^{\circ} \mathrm{N} \\
120.5724^{\circ} \mathrm{W}\end{array}$ & $\begin{array}{l}\text { Coastal Scrub } \\
\text { Cattle farming and } \\
\text { occasional military } \\
\text { traffic }\end{array}$ & $\begin{array}{l}\text { Underwood et al., } \\
2003 ; \\
\text { Weatherspark.com, } \\
2018\end{array}$ \\
\hline
\end{tabular}


Table S2. Summary mass and sex data of $C$. oreganus ( $\mathrm{N}=45$ snakes) used for preferred body temperature $\left(\mathrm{T}_{\text {set }}\right)$ trials, range of temperatures reached during trials, and median site $\mathrm{T}_{\text {set. }}$

\begin{tabular}{|c|c|c|c|c|c|c|}
\hline Site & $n$ & $\begin{array}{l}\text { No. of individuals } \\
\text { with radio } \\
\text { transmitters }\end{array}$ & Sex & Mass Range (g) & $T_{\text {set }} \operatorname{Range}\left({ }^{\circ} \mathrm{C}\right)$ & $\begin{array}{c}\text { Mean } \\
\text { Median } T_{\text {set }}\end{array}$ \\
\hline CR (inland) & 8 & 3 & $\begin{array}{l}M=5 \\
F=3\end{array}$ & $370-790$ & $30.0-36.3$ & 32.25 \\
\hline SG (inland) & 11 & 5 & $\begin{aligned} M & =10 \\
F & =1\end{aligned}$ & $347-912$ & $11.7-36.6$ & 26.47 \\
\hline MDO (coastal) & 15 & 6 & $\mathrm{M}=15$ & $60-860$ & $14.8-37.6$ & 30.55 \\
\hline VAFB (coastal) & 11 & 3 & $\mathrm{M}=11$ & $165-990$ & $15.8-36.7$ & 27.74 \\
\hline
\end{tabular}

Table S3. Behavior states for C. oreganus with their corresponding designations. A behavior was recorded for individual snakes $(\mathrm{N}=28)$ for each observation performed via radio telemetry $(\mathrm{N}=1141)$.

\begin{tabular}{ll}
\hline Behavior & Designation \\
\hline Ambush & $\begin{array}{l}\text { Body in a tightly coiled position } \\
\text { Head facing an obvious game trail }\end{array}$ \\
\hline Basking & $\begin{array}{l}\text { Large amount }(>90 \%) \text { of body exposed to solar radiation } \\
\text { Out in the open }\end{array}$ \\
\hline Hiding & $\begin{array}{l}\text { Hiding inside refugia } \\
\text { Little to no exposure to outside elements }\end{array}$ \\
\hline Resting & $\begin{array}{l}\text { Coiled under plants or shelter } \\
\text { Not facing an obvious game trail }\end{array}$ \\
\hline Transit & Active movement or suspected of movement prior to approach \\
& Elongated body position \\
\hline
\end{tabular}


Table S4. Summary of mean masses and field active body temperatures $\left(T_{b}\right)$ of snakes used for theoretical resting metabolic calculations for each field site. Value followed $\pm 1 \mathrm{SEM}$.

\begin{tabular}{ccccc}
\hline Site & $\boldsymbol{n}$ & Mean mass $(\boldsymbol{g})$ & Mean $\boldsymbol{T}_{\boldsymbol{b}}\left({ }^{\circ} \mathrm{C}\right)$ & $\boldsymbol{T}_{\boldsymbol{b}}$ Range $\left({ }^{\circ} \mathrm{C}\right)$ \\
\hline CR (inland) & 23 & $795.48 \pm 53.91$ & $23.39 \pm 0.23$ & $3.50-37.16$ \\
SG (inland) & 28 & $720.30 \pm 49.25$ & $23.46 \pm 0.20$ & $5.14-69.91$ \\
MDO (coastal) & 15 & $475.24 \pm 42.05$ & $20.93 \pm 0.27$ & $7.00-37.17$ \\
VAFB (coastal) & 19 & $480.51 \pm 21.77$ & $21.80 \pm 0.25$ & $8.00-45.50$ \\
\hline
\end{tabular}




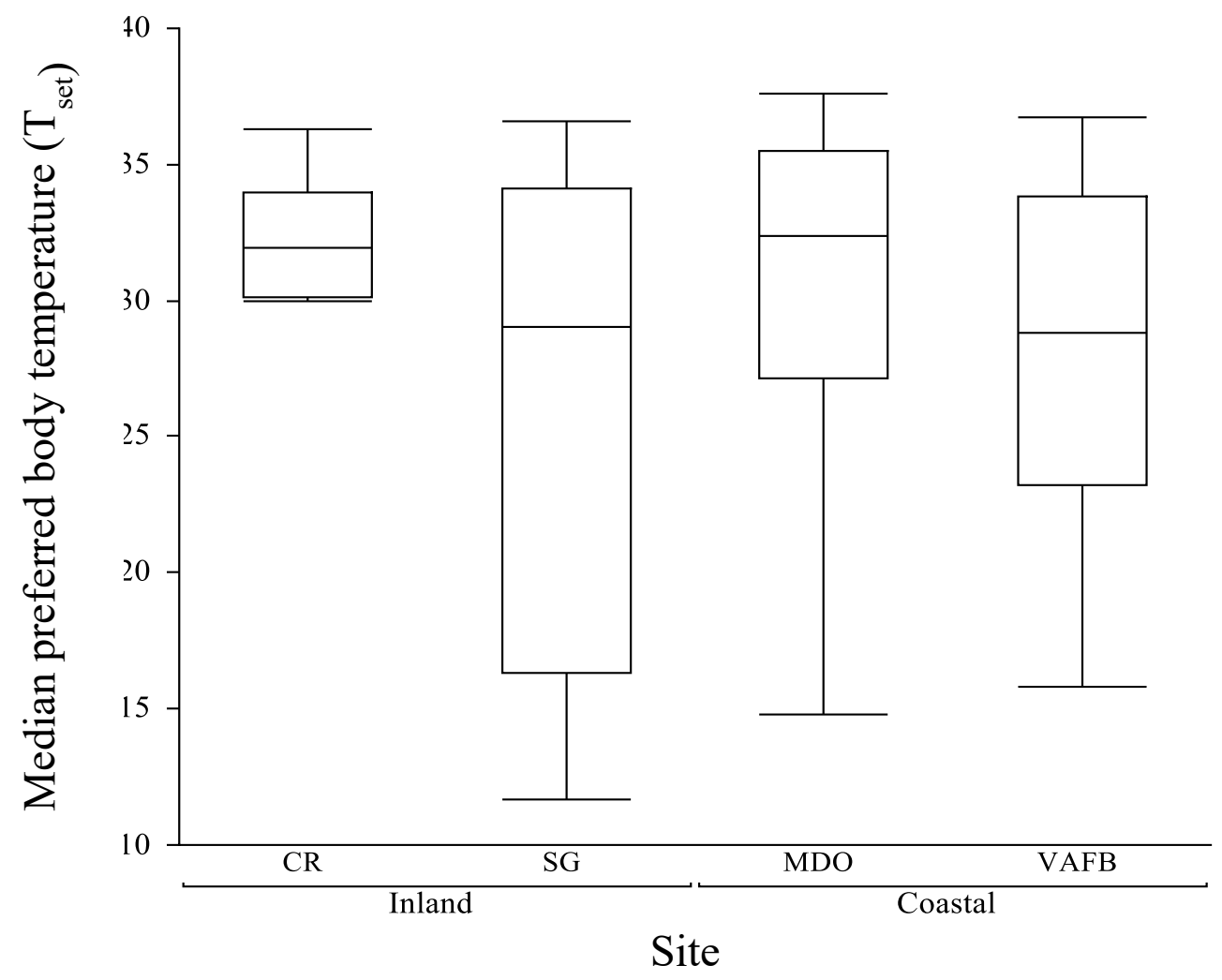

Figure S1. Median preferred body temperatures $\left(\mathrm{T}_{\text {set }}\right)$ of snakes from each site with $25^{\text {th }} \%$ and $75^{\text {th }}$ $\%$ quartiles. There are no significant differences in $\mathrm{T}_{\text {set }}$ among the four sites after taking into account size, sex, presence of internal radio transmitter, and season. The mean $\mathrm{T}_{\text {set }}$ of all populations was $29.22 \pm 0.92{ }^{\circ} \mathrm{C}$ with an interquartile range of $26.3 \pm 1.01-32.3 \pm 0.84^{\circ} \mathrm{C}$. 